\title{
A produção da Análise do Comportamento sobre Surdez/Deficiência Auditiva em periódicos internacionais no período de 1968 a 2018
}

\author{
Production of Behavior Analysis on Deafness/Hearing Impairment in \\ international journals from 1968 to 2018
}

\section{La producción de Análisis de la Conducta en Sordera/Discapacidad Auditiva en revistas internacionales de 1968 a 2018}

\section{Rafael Ernesto Arruda Santos}

Professor doutor dos Centros Universitário UNINASSAU e CESMAC, Maceió, AL, Brasil

E-mail: rafael_ernesto_arruda_santos@hotmail.com ORCID: https://orcid.org/0000-0002-8078-2633

Adriana Ferreira Leal

Graduada pela Universidade Anhembi Morumbi, São Paulo, SP, Brasil

E-mail: contato.adrianaleal@gmail.com ORCID: https://orcid.org/0000-0001-7047-5165

Nassim Chamel Elias

Professor doutor da Universidade Federal de São Carlos, São Carlos, SP, Brasil

E-mail: nchamel@terra.com.br ORCID: https://orcid.org/0000-0003-4197-623X

Recebido em 03 de maio de 2021

Aprovado em 06 de outubro de 2021

Publicado em 29 de outubro de 2021

\section{RESUMO}

A Análise do Comportamento apresenta uma relação histórica com a Educação Especial. Entretanto, algumas revisões indicam uma baixa frequência de estudos sobre surdez e deficiência auditiva, tanto em âmbito nacional como internacional. Nesse contexto, o objetivo desse estudo foi analisar publicações sobre surdez/deficiência auditiva em periódicos internacionais de Análise do Comportamento entre os anos de 1968 a 2018. O método utilizado foi uma revisão de literatura, na qual os passos consistiram em: seleção das revistas internacionais da Association for Behavior Analysis International (ABAI); pesquisa pelos termos internacionais; leitura dos títulos e resumos para aplicação dos critérios de inclusão e exclusão; leitura completa dos textos incluídos para análise de variáveis. As variáveis analisadas foram quantitativas e qualitativas dos resultados apresentados pelos estudos e sua classificação em escolas filosóficas da história da surdez: Oralismo, Comunicação Total ou Bilinguismo. Foram selecionados 30 artigos, sendo 23 sobre pesquisa empírica e 7 sobre pesquisa teórica. Os dados apresentam uma tradição histórica de artigos sobre Análise do Comportamento e surdez ou deficiência auditiva, uma variação significativa nos temas abordados e a influência das escolas filosóficas da história da surdez, apresentando estudos sobre Oralismo, Comunicação Total e Bilinguismo. Discute-se a necessidade de aumentar estudos sobre o tema, seja aplicado ou teórico, e promover novos estudos para a reflexão da relação da Análise do 
http://dx.doi.org/10.5902/1984686X65604

Comportamento com compromissos sociais de abordagens filosóficas do ensino dos surdos.

Palavras-chave: Análise do Comportamento; Surdez; Deficiência Auditiva.

\section{ABSTRACT}

Behavior Analysis has a historical relationship with Special Education. However, some revisions indicate a low frequency of empirical studies on deafness and hearing impairment, both at national and international level. In this context, the objective of this study was to analyze publications on deafness / hearing impairment in international behavioral analysis journals between the years 1968 to 2018 . The method used was a literature review, in which the steps consisted of: selection of international journals listed on the Association for Behavior Analysis International (ABAI) webpage; applying of search terms; reading of titles and abstracts for the application of the inclusion and exclusion criteria; complete reading of the papers selected for analysis. The variables of interest were quantitative and qualitative results presented in the papers and their classification in one or more philosophical schools in the history of deafness: oralism, total communication or bilingualism. From the 30 papers selected, 23 were empirical research and 7 were theoretical. The data indicate a historical tradition of papers on behavioral analysis and deafness or hearing impairment, a significant variation in the topics addressed and the influence of philosophical schools in the history of deafness, presenting studies on oralism, total communication and bilingualism. It is discussed the need to conduct further studies on the subject, whether applied or theoretical, and promote new studies for the reflection on the relationship between behavior analysis and its social commitments of philosophical approaches to teach deaf individuals.

Keywords: Behavior Analysis; Deafness; Hearing Impairment.

\section{RESUMEN}

El análisis de la conducta tiene una relación histórica con la educación especial. Algunas revisiones indican una baja frecuencia de los estudios empíricos sobre la sordera. En este contexto, el objetivo de este estudio fue analizar publicaciones sobre la sordera en las revistas internacionales de análisis de la conducta entre los años 1968 a 2018. El método utilizado fue una revisión de la literatura, con los pasos: selección de revistas internacionales enumeradas en la página web de la Asociación para el Análisis de la Conducta (ABAI); aplicación de los términos de búsqueda; lectura de títulos y resúmenes para la aplicación de los criterios de inclusión y exclusión; lectura completa de los documentos seleccionados. Las variables de interés fueron resultados cuantitativos y cualitativos presentados en los documentos y su clasificación en una o más escuelas filosóficas en la historia de la sordera: oralismo, comunicación total o bilingüismo. De los 30 trabajos seleccionados, 23 fueron investigaciones empíricas y siete teóricas. Los datos indican una tradición histórica de documentos sobre el análisis de comportamiento y la sordera, una variación significativa en los temas abordados y la influencia de las escuelas filosóficas en la historia de la sordera, presentando estudios sobre oralismo, comunicación total y bilingüismo. Se discute la necesidad de realizar estudios adicionales sobre el tema, ya sea aplicados o teóricos, y promover nuevos estudios para la reflexión sobre la relación 
http://dx.doi.org/10.5902/1984686X65604

entre el análisis de la conducta y sus compromisos sociales de los enfoques filosóficos para enseñar a los individuos sordos.

Palabras clave: Análisis de la Conducta; Sordera; Discapacidad auditiva.

\section{Introdução}

Segundo o artigo 58, da Lei no 9.394, de 20 de dezembro de 1996, a Educação Especial é uma modalidade da Educação focada no ensino dos educandos com necessidades especiais, transtornos globais do desenvolvimento e superdotação e/ou altas habilidades (BRASIL, 1996). Nesse contexto, a escola regular deve oferecer serviço de atendimento educacional especializado (AEE) para esses públicos visando sua integração nas classes regulares (BRASIL, 1996). Consequentemente, a Lei no 9.394, de 1996, produz efeito em vários aspectos estruturais da Educação Especial, pois suas diretrizes estabelecem grades curriculares e metodológicas, conclusão do ensino fundamental diferenciada, professores especializados, ensino focado no trabalho para integração social e o acesso aos benefícios de programas sociais (BRASIL, 1996).

Nessa perspectiva, várias abordagens, por exemplo, empírico-analíticas, fenomenológico-hermenêuticas e crítico-dialéticas (GAMBOA, 1998; MARQUES et al., 2008; BARBOSA et al., 2016) e várias propostas metodológicas, por exemplo, pesquisas experimentais, história de vida, etnografia, pesquisa-ação (KAZDIN, 1982; PLETSCH; FONTES; GLAT, 2007; GLAT; PLETSCH, 2009; GAST, 2010; BRAUN, 2012; NUNES, 2014), produzem estudos e conhecimentos visando aprimoramento e melhor qualidade de vida para os estudantes público-alvo da educação especial (PAEE). Entre as várias abordagens, a Análise do Comportamento, mais próxima da abordagem empírico-analítica, apresenta uma relação antiga na produção de conhecimento com e para a Educação Especial.

Kazdin (1982) discute as origens dessa relação entre a Análise do Comportamento e Educação Especial. O surgimento da Análise do Comportamento, a partir dos trabalhos de B. F. Skinner (1904-1990), contribui para uma análise funcional e experimental dos problemas da pesquisa básica e aplicada. Nas décadas de 1950 e 1960, as teorias do comportamento se atrelam ao delineamento com o sujeito como seu próprio controle e o fortalecimento da pesquisa experimental na área forma suas raízes com o surgimento de estudos e revistas. Nos anos de 1960, as pesquisas aplicadas começam a emergir com pacientes psiquiátricos, com Deficiência Intelectual (DI), com Transtorno do Espectro do 
http://dx.doi.org/10.5902/1984686X65604

Autismo (TEA) e outras populações (KAZDIN, 1982). Nesse sentido, as aplicações dos princípios do condicionamento operante emergem com estudos na Educação e na Educação Especial em meados dos anos 1960.

A relação da Análise do Comportamento com a Educação Especial pode ser identificada em livros (por exemplo, KAZDIN, 1982; GAST, 2010) ou em artigos (por exemplo, NELSON; POLSGROVE, 1984; BALLARD, 1987; SULZER-AZAROFF; GILLAT, 1990; HORNER et al., 2005; AGUIAR et al., 2011; TRUMP et al., 2018). Ballard (1987) descreve dois argumentos que ajudariam a explicar a eficácia da Análise do Comportamento com indivíduos do PAEE. O primeiro argumento está na base da teoria comportamental, que define que o comportamento é influenciado pelos ambientes físico e social em que o indivíduo está inserido, sendo que os comportamentos podem ser alterados, se o ambiente também for alterado. Nessa lógica, todos os seres vivos são capazes de ter seu comportamento modificado quando as contingências adequadas são apresentadas ao indivíduo. Esta lógica colabora para um novo olhar para o PAEE, pois sinaliza que todos os seres humanos podem aprender novos repertórios.

O segundo argumento de Ballard (1987) está na aplicação e na efetividade do delineamento, tendo o sujeito como seu próprio controle. A utilização desse tipo de delineamento apresenta uma segurança na validade externa e interna dos experimentos, além de avaliações e correções periódicas pelo aplicador (GAST, 2010). As consequências dessa efetividade afetaram a política educacional, o treinamento de professores, os métodos de ensino e até leis baseadas na Análise do Comportamento nos EUA (BALLARD, 1987).

Dessa forma, a relação entre a Análise do Comportamento e Educação Especial é histórica, com novo olhar para o PAEE e baseado no delineamento de sujeito único. Entretanto, se o PAEE é formado por vários indivíduos com especificidades distintas, por exemplo, com deficiência visual ou auditiva, com TEA, ou com superdotação, já há na literatura produções da Análise do Comportamento para todas essas especificidades? A resposta pode emergir da análise dos materiais citados e das revisões sistemáticas ou de literatura da área.

Trump et al. (2018) descreve a eficácia da Análise do Comportamento Aplicada (Applied Behavior Analysis - ABA) com a população com TEA. Ao descrever os pormenores da relação da $A B A$ com TEA, os autores apresentam dois argumentos sobre essa relação 
http://dx.doi.org/10.5902/1984686X65604

e sua eficácia: (i) os trabalhos de Ivar Lovaas (1987) e (ii) o aumento da exigência dos planos de saúde nos EUA pelo serviço com intervenção comportamental aplicada.

Os efeitos dessa relação refletem em revisões da área com temas como aspectos metodológicos (GOULART; ASSIS, 2002), comportamento verbal em indivíduos com TEA (MARTONE; SANTOS-CARVALHO, 2012; GUERRA; ALMEIDA-VERDU, 2016) e revisão sistemática sobre TEA e ABA (FERNANDES; AMATO, 2013). Em geral, essas revisões apresentam um panorama específico da Análise do Comportamento e sua relação com o TEA. A revisão de Nicolino e Zanotto (2010), por sua vez, apresenta dados comparativos entre os diversos PAEE no Journal of Applied Behavior Analysis (JABA).

Nicolino e Zanotto (2010) pesquisaram na revista internacional JABA, a relação da Análise do Comportamento e a Educação Especial/Inclusiva no período de 2001 a 2008. As etapas do método consistiram na procura pelos artigos na página da revista, leitura dos artigos baseados no critério de aplicação em sala de aula e inclusão do PAEE. Nessa perspectiva, os estudos foram analisados pela quantidade de participantes, idade, diagnóstico da necessidade especial, tipo e delineamento de pesquisa, agente de mudança/observação, local/ambiente, medida do comportamento-alvo, procedimento de intervenção comportamental, tema de pesquisa e análise qualitativa dos artigos. Os resultados apresentaram um retorno de 46 artigos, sendo 27 artigos (59\%) sobre o TEA, enquanto os estudos de outras categorias (Deficiência Intelectual, Atraso do Desenvolvimento, Deficiência Física, Transtornos Psiquiátricos, Síndrome de Down e Transtorno de Déficit de Atenção e Hiperatividade) correspondem aos $41 \%$ restantes. Os autores não encontraram dados sobre a população com deficiência auditiva ou surdez.

Em trabalho posterior, Nicolino e Zanotto (2011) verificaram trabalhos nacionais e analisaram a relação da Análise do Comportamento com a Educação entre 1961 a 2006 e, dentro desse tema, abordaram também a Educação Especial. Os periódicos pesquisados incluíram revistas atuais de Análise do Comportamento, revistas históricas da área descritas em artigos sobre a história da Análise do Comportamento no Brasil e revistas de Psicologia com circulação de trabalhos da área. As variáveis analisadas foram quanto ao número de publicação por autor, filiação, modalidade de educação, tipo de artigo e de pesquisa, ambiente, participantes, agente de mudança/observação, procedimento e tema. Dentro da modalidade da educação especial, somente a variável faixa etária foi analisada especificamente. Foram encontrados 71 artigos, sendo 17 artigos (24\%) sobre Educação Especial. Os autores não identificaram qual o PAEE envolvido nos estudos sobre Análise 
http://dx.doi.org/10.5902/1984686X65604

do Comportamento e Educação Especial no Brasil. Os dados apresentados sobre o tema discorrem sobre habilidade acadêmica, linguagem e habilidades de ensino, e tem como faixa etária crianças com até 5 anos de idade.

Santos e Elias (2019) avaliaram o impacto das intervenções da Análise do Comportamento na Educação Especial em revistas brasileiras da área entre 2008 a 2018. Os autores realizaram uma revisão sistemática do tema e encontraram 39 artigos, sendo 19 sobre surdez/deficiência auditiva, 19 sobre TEA e 3 sobre deficiência intelectual. Nenhum estudo sobre altas habilidades/superdotação, deficiência física, deficiência visual, deficiências múltiplas e surdocegueira foi encontrado segundo os critérios de inclusão estabelecidos para o artigo. Os resultados apresentam a surdez/deficiência auditiva e o TEA como o público mais prevalente nos estudos nacionais e um aumento de estudos sobre TEA ao longo dos anos. De forma geral, os estudos valorizam: delineamento de sujeito único como ambiente mais comum à escola e a prevalência de estudos experimentais. As análises qualitativas mostram uma influência muito grande dos trabalhos de Sidman (1971; 1994; SIDMAN; TAILBY, 1982), no tema da equivalência de estímulos com surdos, a emergência de estudos focados no treinamento dos cuidadores de TEA, e estudos sobre alimentação com o público com deficiência intelectual. Os autores observam a necessidade de explorar mais sobre essa relação da Análise do Comportamento com PAEE, principalmente em temas pouco explorados como surdez, surdocegueira, deficiência física e deficiência visual. Uma vez que a pesquisa focou em estudos brasileiros em revistas brasileiras sobre Análise do Comportamento e Educação Especial, os autores enfatizam a necessidade de expandir essas análises.

Os dados da dissertação de Nóbrega (2018) indicaram 9 teses e dissertações focadas em temas relacionados à Educação Especial e Análise do Comportamento, no período de 2005 a 2015, no Brasil. A maioria dos estudos apresenta uso do procedimento de escolha de acordo com o modelo (MTS, do inglês matching-to-sample). Quanto ao PAEE: 3 estudos foram sobre Deficiência Intelectual, 2 estudos com participantes com Síndrome de Down, 2 estudos com participantes com TEA, 1 com participantes surdos e 1 com bebês com atraso de desenvolvimento.

Esteves, Lucchesi e Almeida-Verdu (2014) debatem a falta de estudos sobre deficiência auditiva e Análise do Comportamento em revisão no JABA sobre os operantes verbais: ecoico, tato e mando. Os autores apresentam dados sobre o PAEE em 45 artigos, sendo 22 artigos (49\%) sobre TEA e apenas 2 (4\%) sobre deficiência auditiva. 
http://dx.doi.org/10.5902/1984686X65604

Em resumo, os estudos sobre Análise do Comportamento estão mais centrados no TEA e quando envolvem o público com deficiência auditiva/surdez, estão focados no tema do implante coclear (CEDRO; PASSARELLI; HUZIWARA, 2014; ESTEVES; LUCCHESI; ALMEIDA-VERDU, 2014; CRAVO et al., 2018). Nesse contexto, se considerarmos a produção expressiva de estudos sobre o ensino de repertórios acadêmicos em matemática ou português, na produção brasileira de Análise do Comportamento (SANTOS; ELIAS, 2019) e as escolas filosóficas educacionais da surdez ${ }^{1}$, poderiam as produções internacionais em periódicos da Análise do Comportamento apresentar resultados semelhantes ao da realidade brasileira? Adicionalmente, surgem outras três perguntas: Haveria uma postura ou defesa de alguma escola educacional da surdez? Seriam os trabalhos sobre oralismo, comunicação total ou bilinguismo? Ou estariam os trabalhos isentos de compromisso social educacional?

Nessa perspectiva, o presente estudo teve como objetivo analisar artigos sobre surdez/deficiência auditiva em periódicos internacionais de Análise do Comportamento entre os anos de 1968 a 2018. Os estudos foram analisados em variáveis quantitativas e qualitativas e categorizados em posturas da filosofia educacional da surdez, de acordo com as informações coletadas nos artigos.

\section{Método}

O método consistiu de uma revisão sistemática de literatura, com passos de pesquisa definidos na procura dos artigos no site das revistas, leitura do título e resumo para aplicar critérios de inclusão e exclusão, armazenamento dos artigos incluídos, leitura integral dos textos incluídos e análise das variáveis quantitativas e qualitativas.

As revistas internacionais pesquisadas foram a European Journal of Behavior Analysis (EJOBA), Journal of Applied Behavior Analysis (JABA), Journal of Behavior Education (JOBE), Perspective on Behavior Science (POBS), The Psychological Record (Psy. Rec.), The Analysis of Verbal Behavior (TAVB) e Behavior Analysis in Practice (BAP). Estas revistas são publicadas ou recomendadas pela Association for Behavior Analysis International (ABAI) e publicam trabalhos com foco em pesquisa aplicada. O período entre 1968 a 2018 foi escolhido por causa da data de fundação da revista mais antiga (Journal of Applied Behavior Analysis) até o ano de coleta destes dados (2019), dessa forma, o recorte apresenta uma evolução história das publicações e uma ampliação necessária para o objetivo deste estudo. 
http://dx.doi.org/10.5902/1984686X65604

O primeiro passo da revisão consistiu na pesquisa nos campos de busca das revistas, utilizando os termos: "deaf", "hard of hearing" e "hearing impairment". Os termos foram pesquisados separados, o que atribui três valores quantitativos de artigos por revista. Nesse caso, foi realizada a análise de artigos duplos e removidos para chegar a uma quantidade consensual da pesquisa dos três termos.

Após a definição da quantidade de artigos sem os artigos duplos, a leitura dos títulos e resumo foi realizada para aplicar o critério de exclusão. Foram retirados artigos de revisão de literatura ou sistemática, artigos teóricos com temas não focados na surdez, resenhas, artigos empíricos sobre outro público e estudos com surdez atrelada à perda de visão (surdocego) ou outras deficiências (múltipla deficiência). Os artigos teóricos que apresentaram um parágrafo ou mais descrevendo exemplos, aspectos teóricos ou empíricos da surdez, deficiência auditiva ou língua de sinais foram incluídos. Entretanto, se o artigo teórico somente citasse estudos sobre surdez para exemplificar aplicações ou validade externa da Análise do Comportamento, esse artigo foi excluído.

A inclusão do artigo automaticamente viabilizava seu armazenamento no computador para leitura do artigo completo. A leitura completa do artigo foi realizada focada nas seguintes variáveis (NICOLINO; ZANOTTO, 2010): a) número de participantes; b) tipo de pesquisa (básica, aplicada ou conceitual, histórica e metodológica); c) delineamento (experimental ou descritivo); d) agente da mudança (experimentador, agente educacional, próprio participante, pais, colegas); e) ambiente da coleta; f) resposta medida; g) intervenção (aquisição, fortalecimento, estabelecimento de controle de estímulos ou redução de repertórios); h) tema da pesquisa (comportamento acadêmico, de ensinar, conduta, linguagem, social, saúde/segurança ou outros); análise qualitativa, que consistia na apresentação geral do objetivo, procedimentos e resultados alcançados pelo estudo e sua categorização na filosofia educacional.

A análise qualitativa dos artigos utilizou os dados da resposta medida e leitura completa do artigo. Os artigos foram classificados de acordo com a resposta medida, posicionamento durante o texto ou não posicionamento em relação às categorias de escola filosófica da surdez: Oralismo, Comunicação Total, Bilinguismo e não definida (CAPOVILLA, 2000). Se a resposta medida se aproximava da oralização, treino da fala, treino do ouvir, leitura labial ou frase com posicionamento claro e definido, o artigo era classificado como Oralista. Se a resposta medida fosse uma soma de procedimentos de oralização (fala, leitura labial, treino de fala, treino do ouvir), com métodos dos sinais 
(Língua de Sinais, datilologia, etc.) e com sistemas artificiais ou posicionamento claro e definido em alguma frase do artigo, o artigo era classificado como Comunicação Total. A presença da Língua de Sinais no estudo poderia indicar bilinguismo, porém a presença da Língua de Sinais pode fazer parte da Comunicação Total, Bilinguismo ou indefinição (LACERDA, 1998). Dessa forma, o artigo era classificado como Bilinguismo se houvesse uma frase com posicionamento bilíngue ou a utilização de Língua de Sinais como comunicação do participante, assim como aspectos da Cultura Surda (como a presença de intérprete ou professor bilíngue). Caso o artigo tivesse a presença da Língua de Sinais, mas não tivesse clareza do seu posicionamento, o artigo era classificado como não definido com sinais e se o artigo não se encaixasse em nenhuma categoria anterior (Oralismo, Comunicação Total, Bilinguismo ou Não definido com sinais), o artigo era classificado como não definido.

\section{Resultados e discussão}

Após as pesquisas realizadas nas revistas e aplicação dos critérios de inclusão e exclusão, 30 artigos sobre o tema atenderam os objetivos deste trabalho. Inicialmente, houve um retorno de 760 artigos, sendo removidos os duplos $(n=66)$, e então realizada a leitura do título e dos resumos dos artigos para aplicar os critérios de inclusão e exclusão. A Figura 1 apresenta um diagrama das etapas e seus resultados.

Figura 1 - Diagrama das etapas da pesquisa, leitura e análise dos artigos

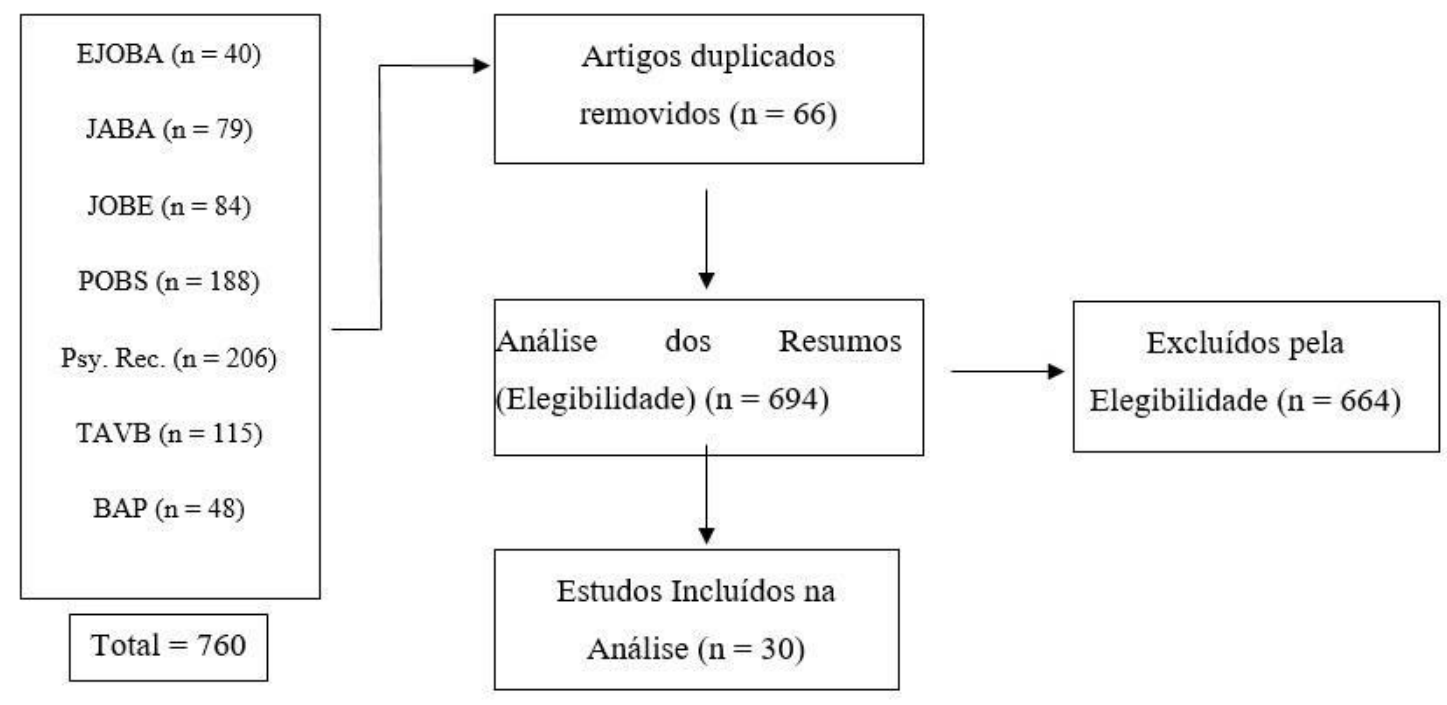

Fonte: Autoria própria (2018). 
http://dx.doi.org/10.5902/1984686X65604

\section{A Tabela 1 apresenta os artigos selecionados, e são exibidos em ordem crescente do} ano de publicação e periódico.

Tabela 1 - Artigos selecionados

(continua)

\begin{tabular}{|c|c|c|c|c|c|c|c|}
\hline ARTIGO & $\begin{array}{c}\text { № DE } \\
\text { PARTICIPANTES }\end{array}$ & $\begin{array}{c}\text { TIPO DE } \\
\text { PESQUISA }\end{array}$ & DELINEAMENTO & $\begin{array}{l}\text { AGENTE DE } \\
\text { MUDANÇA }\end{array}$ & AMBIENTE & $\begin{array}{l}\text { RESPOSTA } \\
\text { MEDIDA }\end{array}$ & $\begin{array}{c}\text { ESCOLA } \\
\text { FILOSÓFICA }\end{array}$ \\
\hline $\begin{array}{l}\text { Osborne } \\
\text { (1969) }\end{array}$ & 6 & Aplicado & Experimental & Experimentador & $\begin{array}{c}\text { Escola } \\
\text { Especial }\end{array}$ & $\begin{array}{l}\text { Sentar na } \\
\text { cadeira }\end{array}$ & Não definido \\
\hline $\begin{array}{l}\text { Craig e } \\
\text { Holland } \\
\text { (1970) }\end{array}$ & 21 & Aplicado & Experimental & Experimentador & Escola & Atenção Visual & Oralismo \\
\hline $\begin{array}{l}\text { Bennett e } \\
\text { Ling (1972) }\end{array}$ & 1 & Aplicado & Experimental & Experimentador & $\begin{array}{l}\text { Escola } \\
\text { Especial }\end{array}$ & $\begin{array}{l}\text { Construção de } \\
\text { Sentenças }\end{array}$ & Oralismo \\
\hline $\begin{array}{l}\text { Wilson e } \\
\text { McReynolds } \\
\text { (1973) }\end{array}$ & 6 & Aplicado & Experimental & Experimentador & $\begin{array}{l}\text { Escola } \\
\text { Especial }\end{array}$ & $\begin{array}{l}\text { Leitura de } \\
\text { Palavras }\end{array}$ & Oralismo \\
\hline $\begin{array}{l}\text { Bennett } \\
\text { (1974) }\end{array}$ & 2 & Aplicado & Experimental & Experimentador & $\begin{array}{l}\text { Escola } \\
\text { Especial }\end{array}$ & $\begin{array}{l}\text { Articulação } \\
\text { Fonética }\end{array}$ & Oralismo \\
\hline $\begin{array}{l}\text { Smeets e } \\
\text { Striefel } \\
(1975)\end{array}$ & 52 & Aplicado & Experimental & Experimentador & $\begin{array}{l}\text { Escola } \\
\text { Especial }\end{array}$ & $\begin{array}{l}\text { Respostas } \\
\text { corretas no } \\
\text { Raven }\end{array}$ & $\begin{array}{l}\text { Não Definido } \\
\text { com Sinais }\end{array}$ \\
\hline $\begin{array}{l}\text { Neef, } \\
\text { Iwata, e } \\
\text { Page } \\
\text { (1980) }\end{array}$ & 3 & Básica & Experimental & Experimentador & $\begin{array}{l}\text { Escola } \\
\text { Especial }\end{array}$ & $\begin{array}{l}\text { Soletração } \\
\text { correta }\end{array}$ & $\begin{array}{l}\text { Não Definido } \\
\text { com Sinais }\end{array}$ \\
\hline $\begin{array}{l}\text { Houten e } \\
\text { Nau (1980) }\end{array}$ & 5 & Aplicado & Experimental & Experimentador & $\begin{array}{l}\text { Escola } \\
\text { Especial }\end{array}$ & Atenção Visual & $\begin{array}{c}\text { Comunicação } \\
\text { Total }\end{array}$ \\
\hline $\begin{array}{l}\text { Michael } \\
\text { (1982) }\end{array}$ & - & Teórico & - & - & - & - & Não Definido \\
\hline $\begin{array}{l}\text { Barnes, } \\
\text { McCullagh } \\
\text { e Keenan } \\
(1990)\end{array}$ & 6 & Básico & Experimental & Experimentador & $\begin{array}{l}\text { Escola } \\
\text { Especial }\end{array}$ & Apontar & $\begin{array}{c}\text { Comunicação } \\
\text { Total }\end{array}$ \\
\hline $\begin{array}{l}\text { Sundberg } \\
\text { (1991) }\end{array}$ & - & Teórico & - & - & - & - & $\begin{array}{c}\text { Comunicação } \\
\text { Total }\end{array}$ \\
\hline $\begin{array}{l}\text { Rasing e } \\
\text { Duker } \\
\text { (1992) }\end{array}$ & 9 & Aplicado & Experimental & Experimentador & Escola & $\begin{array}{l}3 \text { habilidades } \\
\text { sociais }\end{array}$ & $\begin{array}{c}\text { Comunicação } \\
\text { Total }\end{array}$ \\
\hline $\begin{array}{l}\text { Rasing } \\
\text { (1993) }\end{array}$ & 20 & Aplicado & Experimental & Experimentador & Escola & $\begin{array}{l}\text { Replicação do } \\
\text { Rasing \& Duker }\end{array}$ & Oralismo \\
\hline $\begin{array}{l}\text { Wolery et } \\
\text { al. (1993) }\end{array}$ & 5 & Básico & Experimental & Experimentador & Escola & $\begin{array}{c}\text { Comportamento } \\
\text { Alvo }\end{array}$ & Oralismo \\
\hline $\begin{array}{l}\text { Sundberg } \\
\text { (1993) }\end{array}$ & - & Teórico & - & - & - & - & $\begin{array}{c}\text { Comunicação } \\
\text { Total }\end{array}$ \\
\hline $\begin{array}{l}\text { Borthwick- } \\
\text { Duffy, } \\
\text { Palmer e } \\
\text { Lane } \\
(1996)\end{array}$ & - & Teórico & - & - & - & - & Bilinguismo \\
\hline $\begin{array}{l}\text { Ducharme } \\
\text { e Holborn } \\
\text { (1997) }\end{array}$ & 5 & Aplicado & Experimental & Experimentador & $\begin{array}{l}\text { Escola } \\
\text { Especial }\end{array}$ & $\begin{array}{l}\text { Habilidades } \\
\text { sociais }\end{array}$ & Oralismo \\
\hline
\end{tabular}

Revista Educação Especial | v. 34 | 2021 - Santa Maria

Disponível em: https://periodicos.ufsm.br/educacaoespecial 
Tabela 1 - Artigos selecionados

(conclusão)

\begin{tabular}{|c|c|c|c|c|c|c|c|}
\hline ARTIGO & $\begin{array}{c}\text { No DE } \\
\text { PARTICIPANTES }\end{array}$ & $\begin{array}{l}\text { TIPO DE } \\
\text { PESQUISA }\end{array}$ & DELINEAMENTO & $\begin{array}{l}\text { AGENTE DE } \\
\text { MUDANÇA }\end{array}$ & AMBIENTE & $\begin{array}{l}\text { RESPOSTA } \\
\text { MEDIDA }\end{array}$ & $\begin{array}{c}\text { ESCOLA } \\
\text { FILOSÓFICA }\end{array}$ \\
\hline $\begin{array}{l}\text { Shore et al. } \\
\text { (1998) }\end{array}$ & 4 & Aplicado & Experimental & Experimentador & $\begin{array}{c}\text { Residência } \\
\text { Especial }\end{array}$ & $\begin{array}{l}\text { Ingestão de } \\
\text { Alimento }\end{array}$ & Não definido \\
\hline $\begin{array}{l}\text { Ward, } \\
\text { Johnson e } \\
\text { Konukman } \\
\text { (1998) }\end{array}$ & 4 & Aplicado & Experimental & $\begin{array}{c}\text { Agente } \\
\text { Educacional }\end{array}$ & Escola & $\begin{array}{c}\text { Comportamento } \\
\text { de Ensinar }\end{array}$ & Bilinguismo \\
\hline $\begin{array}{l}\text { Mueller, } \\
\text { Edwards e } \\
\text { Trahant } \\
\text { (2003) }\end{array}$ & 3 & Aplicado & Experimental & $\begin{array}{c}\text { Agente } \\
\text { Educacional }\end{array}$ & Escola & $\begin{array}{c}\text { Comportamento } \\
\text { Problema }\end{array}$ & $\begin{array}{c}\text { Comunicação } \\
\text { Total }\end{array}$ \\
\hline $\begin{array}{l}\text { Miller et al. } \\
(2003)\end{array}$ & 3 & Aplicado & Experimental & Pares & Escola & Interação social & Oralismo \\
\hline $\begin{array}{l}\text { McCarty } \\
(2004)\end{array}$ & - & Teórico & - & - & - & - & Bilinguismo \\
\hline $\begin{array}{l}\text { Greer e } \\
\text { Speckman } \\
(2009)\end{array}$ & - & Teórico & - & - & - & - & Não definido \\
\hline $\begin{array}{l}\text { Mann, } \\
\text { Bushell e } \\
\text { Morris } \\
(2010)\end{array}$ & 5 & Aplicado & Experimental & Experimentador & Escola & $\begin{array}{l}\text { Soletração } \\
\text { correta }\end{array}$ & Oralismo \\
\hline $\begin{array}{l}\text { Hammond } \\
\text { et al. } \\
\text { (2011) }\end{array}$ & 4 & Aplicado & Experimental & Experimentador & $\begin{array}{c}\text { Escola } \\
\text { Especial }\end{array}$ & $\begin{array}{c}\text { Comportamento } \\
\text { Problema }\end{array}$ & Não definido \\
\hline $\begin{array}{l}\text { Fritz et al. } \\
\text { (2013) }\end{array}$ & 16 & Aplicado & Experimental & Experimentador & $\begin{array}{c}\text { Escola } \\
\text { Especial }\end{array}$ & $\begin{array}{c}\text { Comportamento } \\
\text { Problema }\end{array}$ & $\begin{array}{c}\text { Não Definido } \\
\text { com Sinais }\end{array}$ \\
\hline $\begin{array}{l}\text { Kurtz et al. } \\
\text { (2013) }\end{array}$ & 52 & Aplicado & Experimental & Pais & $\begin{array}{c}\text { Residência } \\
\text { Especial }\end{array}$ & $\begin{array}{c}\text { Comportamento } \\
\text { Problema }\end{array}$ & Não definido \\
\hline $\begin{array}{l}\text { Elias e } \\
\text { Goyos } \\
(2013)\end{array}$ & 5 & Básico & Experimental & Experimentador & Escola & $\begin{array}{l}\text { Imitação } \\
\text { mimética }\end{array}$ & $\begin{array}{c}\text { Não Definido } \\
\text { com Sinais }\end{array}$ \\
\hline $\begin{array}{l}\text { Golfeto e } \\
\text { Souza } \\
(2015)\end{array}$ & 3 & Aplicado & Experimental & Experimentador & $\begin{array}{c}\text { Não } \\
\text { definido }\end{array}$ & $\begin{array}{l}\text { Vocalização de } \\
\text { Sentenças }\end{array}$ & Oralismo \\
\hline $\begin{array}{l}\text { Baum } \\
(2018)\end{array}$ & - & Teórico & - & - & - & - & Não definido \\
\hline
\end{tabular}

Fonte: Autoria própria (2018).

Dos 30 artigos, 23 artigos são empíricos e 7 são teóricos. As variáveis analisadas dos artigos teóricos foram: ano e análise qualitativa. Para os artigos empíricos, foram analisadas todas as variáveis apresentadas no método. Por este motivo, algumas figuras a seguir têm o total de 30 ou 23 artigos analisados. Os estudos empíricos na análise qualitativa foram divididos em dois subgrupos: multiforme e uniforme. O grupo multiforme consiste na apresentação de estudos com vários participantes, incluídos outros participantes do PAEE ou com desenvolvimento típico, além dos participantes surdos ou com deficiência auditiva. 
Por outro lado, o grupo uniforme apresenta dados de estudos somente com participantes surdos ou com deficiência auditiva. Dessa forma, três grupos de estudos foram analisados: estudos teóricos, estudos empíricos multiformes e estudos empíricos uniformes.

As revistas EJOBA e BAP não apresentaram estudos para inclusão. A maior taxa de artigos foi registrada no JABA $(n=18)$, em seguida com taxas menores de artigos aparecem TAVB $(n=5)$, JOBE $(n=4)$, Psy. Rec. $(n=2)$ e, por último, POBS $(n=1)$.

Em relação ao tipo de pesquisa, a maioria dos estudos é aplicada $(n=19)$, em segundo lugar vêm os estudos teóricos/metodológicos/históricos $(n=7)$, e por último os estudos básicos $(n=4)$. Esses resultados assemelham-se aos de Nicolino e Zanotto (2010), que mostram uma maioria de estudos focados na área aplicada ( $n=41)$, poucos estudos básicos $(n=5)$, mas nenhum estudo na categoria teórico/metodológico/histórico. A diferença dos resultados para estudo teórico/metodológico/histórico reside na diferença do objetivo dos dois estudos. Nicolino e Zanotto (2010) pesquisaram artigos sobre o PAEE somente na revista JABA, sendo esta revista conhecida pela aplicação de princípios da Análise do Comportamento para demandas originadas da sociedade. Nesta lógica, os resultados encontrados no presente estudo confirmam a prevalência dos aplicados na taxa de retornos na revista JABA $(n=18)$. Entretanto, como o presente estudo verificou a ocorrência destes artigos em outras revistas da área, 7 artigos foram encontrados em revistas como TAVB $(n=4)$, JOBE $(n=1)$, POBS $(n=1)$, e Psy. Rec $(n=1)$.

Vale ressaltar que a revista JABA tem como escopo artigos aplicados, o que enviesaria a quantidade de artigos para a análise. Uma análise das outras revistas sem a quantidade de artigos do JABA fornece os seguintes dados: 7 artigos sobre tema teórico/metodológico/histórico, 3 artigos sobre pesquisas básicas e 2 artigos sobre pesquisas aplicadas. A eficácia da aplicabilidade da Análise do Comportamento não pode ser inferida somente por estudos publicados no JABA, analisados pelo presente capítulo e no estudo de Nicolino e Zanotto (2010), mas a inclusão dos estudos de outras revistas, mesmo teórico, básico e aplicado, demonstra a relevância social da Análise do Comportamento e sua aplicação em vários contextos, dando validade externa para o método experimental com delineamento de sujeito único (identificado na maioria dos estudos selecionados) e mostrando sua relação histórica com a Educação Especial (HORNER, 1997).

A Tabela 1 também apresenta os dados sobre o agente de mudança do experimento. A maioria dos artigos $(82,6 \%)$ apresenta o experimentador como principal agente de 
http://dx.doi.org/10.5902/1984686X65604

mudança. Esses dados assemelham-se aos de Nicolino e Zanotto (2010), no qual a categoria "experimentador" teve mais taxas de artigos.

Os dados sobre o ambiente no qual a pesquisa empírica foi realizada também é apresentada na Tabela 1. A maior parte dos estudos foi realizada em Escolas Especiais (47,8\%) ou Escolas Regulares (39,1\%), 2 estudos coletaram os dados em uma residência especial e 1 não definiu o local de coleta. A aplicação dos princípios da Análise do Comportamento em Escolas e Escolas Especiais demonstra a relação entre a abordagem e a Educação, e a Educação Especial. Os dados se assemelham aos de Nicolino e Zanotto (2010) e Santos e Elias (2019). A variação de locais de coleta colabora também para a validação externa dos estudos e demonstração da eficácia do delineamento de sujeito único. Os dados não apresentam aplicações dos estudos em contextos como casa do participante, clínica ou outro local.

As respostas medidas pelos estudos representam qual variável dependente era analisada pelos pesquisadores, o que indica aproximação com o tema pesquisado e da qual se pode derivar a postura filosófica educacional adotada pelos autores. Os temas encontrados são bastante variados, sendo 4 estudos sobre comportamentos problemas, 2 sobre habilidades sociais, 2 sobre atenção visual e 1 estudo para cada um dos seguintes temas: ingestão de alimentos; sentar na cadeira; construção de sentenças; leitura de palavras; articulação fonética; respostas corretas nas matrizes progressivas de raven; vocalização de sentenças; comportamento alvo; comportamento de ensinar; interação social; imitação mimética; e apontar.

Santos e Elias (2019) não fazem uma análise mais detalhada das respostas medidas nos estudos nacionais sobre o tema, mas identificaram estudos sobre escolha de acordo com o modelo e suas variações, que utilizam ou ensinam respostas de apontar ou nomear os objetos, como também estudos sobre o comportamento verbal. Os estudos nacionais selecionados por Santos e Elias (2019) apresentam temas mais específicos da área de controle de estímulos e comportamento verbal, o que difere dos temas variados dos estudos internacionais deste presente estudo. Esses dados sugerem que pesquisas nacionais ainda precisam investir em estudos com temas mais variados ao se aplicar a Análise do Comportamento para indivíduos do PAEE.

Em suma, esses dados sobre as respostas medidas demonstram a variabilidade de temas e complexidade dos estudos sobre Análise do Comportamento e surdez, apesar das críticas direcionadas à abordagem, geralmente citada como uma abordagem simplista e 
http://dx.doi.org/10.5902/1984686X65604

reducionista (CARRARA, 2015). As respostas medidas apresentam aspectos importantes para contrapor essas afirmativas e apresentar respostas como interação social e habilidade social, por exemplo, como uma resposta adequada para a sobrevivência dos surdos na comunidade social.

Em relação ao tipo de intervenção aplicada, os dados apresentam 9 artigos que focaram no fortalecimento de um repertório pré-estabelecido nos participantes, 8 artigos sobre aquisição de novos repertórios e 4 artigos sobre redução de repertório. Em último, a categoria controle de estímulos com 2 artigos. Esses dados estão em consonância com Nicolino e Zanotto (2010), pois os artigos internacionais analisados refletem a ocorrência das intervenções de aquisição e fortalecimento de repertórios em diversos públicos. Em contrapartida, os dados de Santos e Elias (2019) sobre surdez/deficiência auditiva apresentam uma prevalência de estudos sobre controle de estímulos, ou seja, os artigos nacionais têm uma influência estabelecida pelos trabalhos de Sidman (1994; SIDMAN; TAILBY, 1982), sendo utilizados os princípios da equivalência de estímulos (SIDMAN, 1994) para resolução de aplicações educacionais na matemática, no português e na articulação de fala (SANTOS; ELIAS, 2019). O estudo de Nicolino e Zanotto (2010) também registra uma taxa alta $(47,8 \%)$ de estudos com intervenção em controle de estímulos. As diferenças entre intervenções por nacionalidade são ocasionadas, provavelmente, por fatores sociais no estabelecimento de pesquisas de Análise do Comportamento. Os estudos sobre redução de respostas são todos com grupos multiformes (mais detalhes na seção de análise qualitativa), ou seja, focavam em comportamentos problemas para um grupo maior do PAEE em instituições ou escolas especiais.

A Tabela 1 apresenta dados sobre o tema das pesquisas. A maioria dos estudos está focada em temas educacionais, por exemplo, comportamentos acadêmicos ( $n=7)$ e comportamento de ensinar $(n=8)$. Em seguida, os temas Saúde/Segurança e Comportamento Social, cada um com 4 artigos. Os dados de Nicolino e Zanotto (2010) apresentam a linguagem como o tema mais prevalente. Em Santos e Elias (2019), os temas se dividem em dois grupos: os treinos de ouvir para deficiente auditivo com implante coclear e uso de Libras para ensino de matemática ou português. Os dados apresentados nessa revisão apresentam discrepância de tema, provavelmente em decorrência do PAEE e da nacionalidade dos estudos. Nicolino e Zanotto (2010) não apresentam dados sobre surdos/deficiência auditiva, mas uma alta taxa de estudos sobre TEA, ou seja, a linguagem 
é um tema recorrente na área (MARTONE; SANTOS-CARVALHO, 2012; GUERRA; ALMEIDA-VERDU, 2016)

Santos e Elias (2019), que analisaram os artigos nacionais sobre surdez/deficiência auditiva, apresentam dados semelhantes. Os estudos focados no treino do ouvir e no uso da Libras para controle de estímulos colabora para uma taxa alta de comportamento de ensinar e linguagem. Dessa forma, os estudos nacionais e internacionais sobre os surdos têm um foco mais direcionado para contextos acadêmicos e de ensino, como também para o principal fator de diferença entre surdos e ouvintes: a linguagem falada versus a linguagem visuo-espacial.

A Figura 2 apresenta a quantidade de artigos por ano de publicação, sendo que os anos de 1993 e 2013 tiveram a maior taxa de artigos publicados $(n=3)$, seguidos pelos anos 1980, 1998 e 2003 (n=2). Entretanto, dos 50 anos pesquisados, há 26 anos (52\%) em que nenhuma publicação foi encontrada (1971, 1976 a 1979, 1981, 1983 a 1989, 1994, 1995, 1999 a 2002, 2005 a 2008, 2012, 2014, 2016 e 2017). A maior parte dos estudos se concentra nos anos da década de 90 . Nesta lógica de análise, futuras pesquisas poderiam avaliar a relação entre publicações de artigos da Análise do Comportamento sobre PAAE e leis internacionais sobre Educação Especial, assim verificando a relação entre dispositivos legais e produção de conhecimento em ambas as áreas.

Figura 2 - Quantidade de artigos por ano de publicação

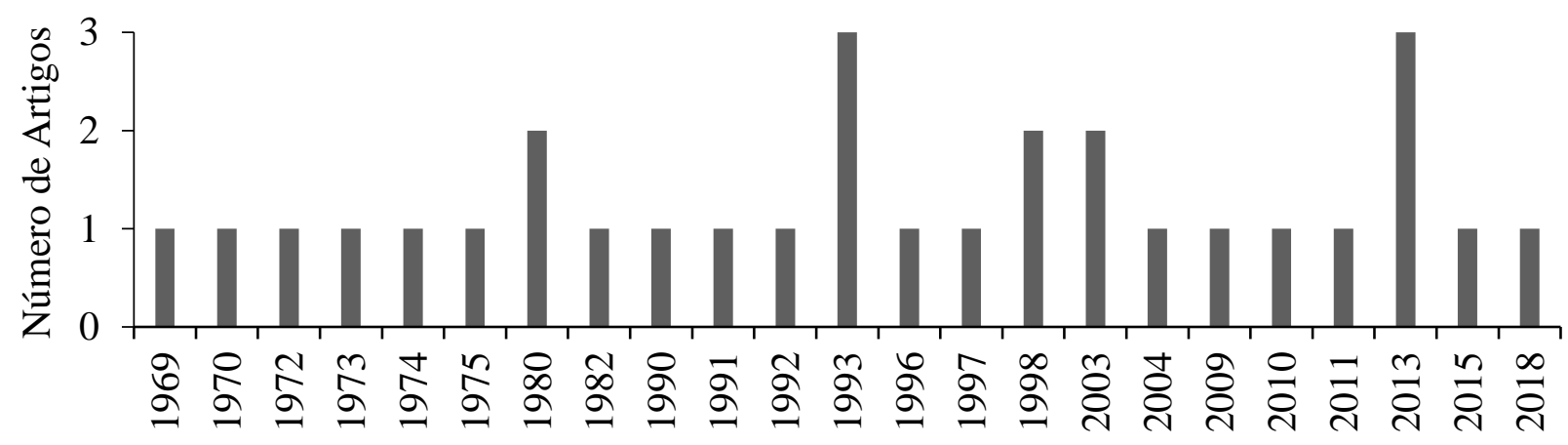

Ano de Publicação

Fonte: Autoria própria (2018).

A análise do número de participantes ocorreu somente para artigos empíricos ( $n=23)$, sendo seu resultado apresentado na Figura 3. A maioria dos estudos empíricos aplicou as variáveis de 3 a 6 participantes, sendo a quantidade de 5 participantes com a maior taxa entre todos, ocorrendo registros de estudos com 1, 2 e 9 participantes. Nesse contexto, 
http://dx.doi.org/10.5902/1984686X65604

ocorreram registros de estudos com $16(n=1), 20 \quad(n=1), 21 \quad(n=1)$ e até $52(n=2)$ participantes.

Figura 3 - Quantidade de artigos por número de participantes

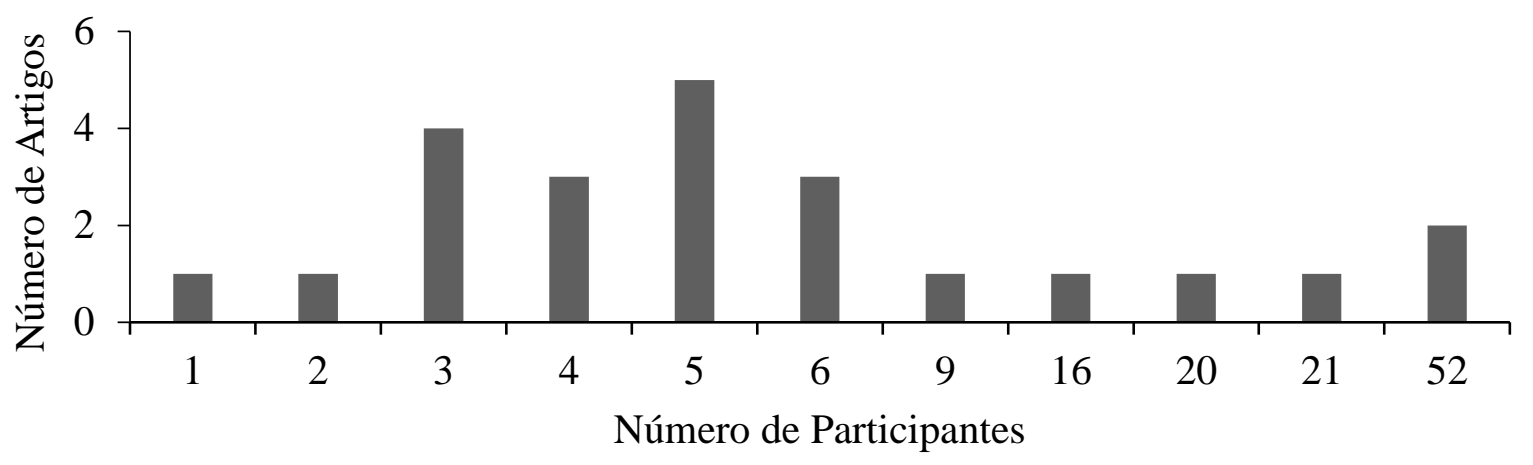

Fonte: Autoria própria (2018).

De acordo com Nicolino e Zanotto (2010), o destaque para a quantidade baixa de participantes nos estudos em Análise do Comportamento é atribuído aos delineamentos que tem o sujeito como seu próprio controle. Na revisão dos autores, as maiorias dos estudos tinham até quatro participantes, sendo o procedimento experimental e a análise de dados feitos a partir dos dados de desempenho inicial do participante, intervenção e desempenho final do mesmo. Primeiro, o participante é submetido aos testes iniciais para mensurar o desempenho, em seguida é aplicada a fase de ensino ou intervenção, e por último, os testes finais apresentam os resultados após a intervenção. Essa dinâmica experimental permite ao pesquisador avaliar o sujeito com ele mesmo (GAST, 2010).

Sob o mesmo ponto de vista, as revisões de Cedro, Passarelli e Huziwara (2014), de Guerra e Almeida-Verdu (2016) e de Martone e Santos-Carvalho (2012) apresentam estudos com variação entre um até oito participantes por estudo, ratificando a eficácia e eficiência dos delineamentos que tem o sujeito como seu próprio controle para pesquisadores e usuários dos serviços e pesquisas da Análise do Comportamento. Os dados desta revisão ratificam também a importância dos delineamentos de sujeito único para o público surdo ou deficiente auditivo.

Em contrapartida, alguns estudos apresentaram entre 16, 20, 21 ou até 52 participantes. O estudo de Fritz et al. (2013; $n=16)$ e Craig e Holland (1970; $n=21)$ tiveram vários experimentos dentro do artigo, consequentemente acarretando em número mais elevado de participantes, mas utilizando delineamento de sujeito único. Os estudos de Rasing (1993; $\mathrm{n}=20$ ) e Smeets e Striefel (1975; $\mathrm{n=52)}$ utilizaram delineamentos com grupo controle e/ou vários grupos experimentais com condições diferentes. O estudo de Kurtz et al. (2013) avaliou 
52 casos de participantes utilizando análise funcional e delineamento de sujeito único. Dessa forma, apesar de cinco estudos (o que corresponde a 17\% dos estudos selecionados) apresentarem de 16 a mais participantes, somente 2 estudos (o que corresponde a $7 \%$ dos estudos selecionados) apresentam delineamento com grupo controle. Esses dados assemelham-se aos de Santos e Elias (2019), no qual, os experimentos com participantes com deficiência intelectual ou surdez/deficiência auditiva apresentaram estudos com grupo controle e experimental para comparação de dados (7,6\%).

A figura 4 apresenta a quantidade de artigos empíricos e o delineamento de sujeito único adotado, entre eles, modelos variantes da ABA e delineamentos de linha de base múltipla. Os dados apresentam uma aproximação maior para delineamentos do tipo ABA e $A B A B$, tratamento alternado, múltipla sondagem e linha de base múltipla entre comportamentos. Esses dados mostram a variabilidade do delineamento de sujeito único e sua capacidade, como modelo experimental, para atender demandas sociais relevantes para a aplicação. Dessa forma, o delineamento de sujeito único aparece com frequência em estudos com o PAEE, seja no TEA ou na surdez, e se sobrepõe em relação aos estudos com grupo controle e experimental. Consequentemente, esta prática reflete na divulgação e promoção da Análise do Comportamento, tornando-se necessário em futuras análises verificar se o delineamento de sujeito único é utilizado por pesquisadores externos à Análise do Comportamento.

Figura 4 - Quantidade de artigos empíricos de acordo com o delineamento experimental

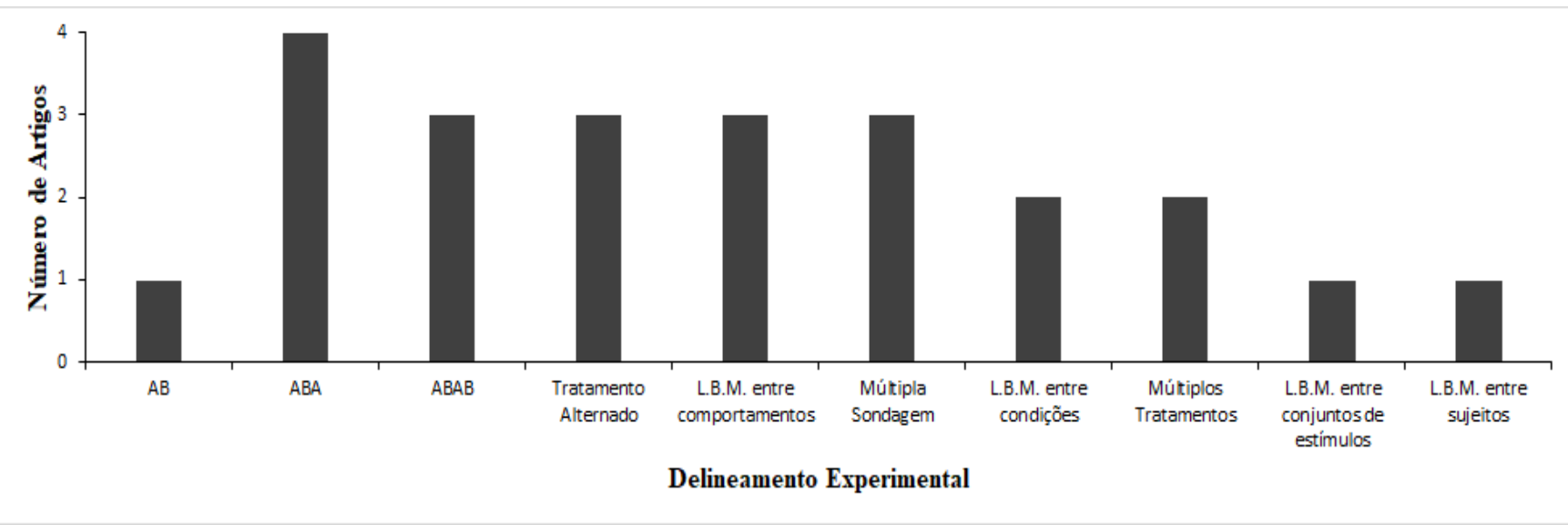

Fonte: Autoria própria (2018).

Em resumo, os artigos sobre surdez nas revistas de Análise do Comportamento nacionais (ver SANTOS; ELIAS, 2019) e internacionais utilizados nesta pesquisa utilizam do método experimental e, na sua maioria, de delineamento de sujeito único. Esse dado é 
http://dx.doi.org/10.5902/1984686X65604

o oposto da realidade da produção de conhecimento na Educação Especial no Brasil (GLAT; OMOTE; PLETSCH, 2014). Glat, Omote e Pletsch (2014) analisaram a produção de pesquisadores em congressos de Educação Especial no Brasil e constataram um percentual de apenas $2 \%$ dos estudos como experimentais e uma predominância de $85 \%$ de estudos com métodos descritivos.

Por certo, a maioria de estudos aplicados encontrados nesta pesquisa (63,3\%) sugere um olhar mais prático da Análise do Comportamento no campo da Educação Especial, não só com a surdez, mas com vários grupos do PAEE. É provável que os dados apresentados pelos estudos fomentem pesquisas e colaborem para problemas aplicados à Educação Especial. Nesta perspectiva, as colaborações da Análise do Comportamento podem ser avaliadas qualitativamente nos artigos apresentados. A análise qualitativa dos artigos pode colaborar para um aprofundamento no debate político e metodológico da Análise do Comportamento, principalmente nos seus trabalhos envolvendo o público surdo e suas filosofias educacionais históricas.

\section{Análise qualitativa dos artigos teóricos e empíricos}

Osborne e Wageman (1969) descrevem três premissas importantes para a aplicação de técnicas do condicionamento operante em escolas para surdos: a) a psicologia é o estudo do comportamento; b) os comportamentos são aprendidos e governados por leis da relação ambiente e comportamento; e c) "o comportamento da criança surda é governado pelos mesmos princípios que governam o comportamento dos ouvintes" (OSBORNE; WAGEMAN, 1969, p. 741). Nesta perspectiva, os estudos teóricos encontrados nessa revisão seguem a aplicação da análise funcional e dos princípios da Análise do Comportamento em situações próximas da Comunidade Surda (Cultura) ou da história de vida do surdo (ontogênese). Os estudos descrevem temas como comportamento verbal e língua de sinais (MICHAEL, 1982; SUNDBERG, 1991, 1993; MCCARTY, 2004; GREER; SPECKMAN, 2009), controle de estímulos (BAUM, 2018) e o debate entre inclusão e diferença individual (BORTHWICK-DUFFY; PALMER; LANE, 1996).

Baum (2018) apresenta reflexões filosóficas a respeito do tema da percepção auditiva e o dilema da árvore caindo na floresta. Nessa lógica, Baum (2018) faz uma análise de situações hipotéticas para apresentar sua conclusão, entre elas, coloca uma situação na qual, duas pessoas estão numa sala tocando Mozart. Uma pessoa é ouvinte $(\mathrm{X})$ e outra é surda $(Y)$. Se X e Y estão parados, não há possibilidade de inferir quem está escutando ou 
http://dx.doi.org/10.5902/1984686X65604

não o som, nesse caso seria necessário perguntar para ambos quem gostou ou ouviu 0 som, por exemplo. Baum (2018) sugere a participação de uma terceira pessoa (A). Esta pessoa é ouvinte e observa X e Y. Quando o som está desligado X e Y se comportam de maneira semelhante, mas quando o som está ligado $X$ se movimenta mais e $Y$ não. Se $A$ observa essa diferença na presença e na ausência do som, pode inferir que $X$ é ouvinte $e$ Y é surda. Ademais, Baum (2018) acrescenta mais um observador (B), este é surdo e faz uso de um instrumento para identificar quando tem ou não a presença do som na sala, da mesma forma, B pode inferir que $X$ é ouvinte e $Y$ é surda.

Esse dilema apresentado por Baum (2018) é um exemplo específico, mas tem implicações maiores para uma análise funcional da surdez. A percepção auditiva, aqui interpretada como discriminação simples, é estabelecida por contingências de reforçamento e controle de estímulos de acordo com o contexto do ouvir e do não ouvir. Se os princípios comportamentais são os mesmos para surdos e ouvintes (OSBORNE; WAGEMAN, 1969), em Baum (2018) é possível observar a diferença na ontogênese do surdo: a ausência da percepção do som e a modelação do campo visual.

A maioria dos artigos teóricos sobre surdez analisou questões sobre a língua de sinais como comportamento verbal. A primeira análise é feita por Michael (1982), cuja proposta é categorizar os operantes verbais em códigos e dúplicos, considerando que as categorias definidas por Skinner (1957) poderiam não dar conta de determinados comportamentos verbais, principalmente, alguns cuja topografia da resposta não é falada (por exemplo, gestos ou sinais). A categoria código englobaria o textual e o ditado porque a resposta é controlada por um estímulo verbal, com correspondência ponto-a-ponto e não teria similaridade física entre resposta e estímulo antecedente, ou seja, seriam operantes verbais que se transformariam em códigos de outra dimensão sensorial, por exemplo, escrever aquilo que é falado pelo professor ou ler o que foi escrito por alguém na lousa. Os dúplicos seriam o ecoico e a cópia, a característica dessa categoria seria a resposta sendo controlada por um estímulo verbal antecedente e haveria similaridade formal entre resposta e estímulo antecedente, bem como a correspondência ponto-a-ponto, ou seja, os comportamentos seriam duplicados e repetidos, por exemplo, repetir pela fala o que alguém fala ou copiar uma frase escrita na lousa. Dessa forma, os operantes verbais são classificados em: mando, tato, intraverbal, código e dúplico.

Michael (1982), ao analisar os operantes verbais, faz algumas análises sobre a Língua Americana de Sinais (ASL). O autor define que a resposta nos operantes verbais pode ser a 
fala, a escrita, os sinais, a datilologia, o código Morse, o Braille, etc. Assim sendo, o mando, o tato, o intraverbal, o código e o dúplico poderiam ser observados em línguas de sinais. No intraverbal, por exemplo, os estímulos antecedentes verbais poderiam ser de qualquer dessas categorias assim como a resposta produzida, desde que o controle seja temático e não haja correspondência ponto-a-ponto entre antecedente e resposta. Por exemplo, o professor em sala de aula emite o sinal "Qual animal é um felino?" e então a criança escreve no papel em português ou sinaliza a palavra "gato". O código em língua de sinais seria avaliado pela criação de dicionários em língua de sinais (e.g. CAPOVILLA et al., 2017), por exemplo, o aluno surdo diante do sinal desenhado de "gato" (sign writing) pode sinalizar "GATO" (um exemplo de textual) ou diante da sinalização do professor "GATO" escrever o sinal desenhado "gato" (exemplo de ditado). Na análise dos dúplicos, Michael (1982) separa a repetição falada do que se ouviu (ecoico) da repetição de um sinal (dúplico do tipo mimético), na qual um surdo sinaliza o que outra pessoa acabou de sinalizar.

No tópico sobre a população surda, Sundberg (1991) sugere a linguagem como principal obstáculo do surdo para a vida na sociedade ouvinte. Neste contexto, o autor sugere estudos que avaliem 0 efeito da comunicação total e do oralismo no desenvolvimento do surdo, efeitos da soletração ou sinalização na articulação da fala, ensino dos operantes verbais (mando, tato, intraverbal, código e dúplico), ensino de sinais para ouvintes, o papel da comunidade surda no desenvolvimento da criança surda e estudos sobre ASL como primeira língua e o inglês escrito como segunda (bilinguismo). 0 autor também sugere estudos sobre a escrita de sinais (sign writing) e avalia esse efeito no estabelecimento de operantes verbais textuais e ditados. Adicionalmente, Sundberg (1991) traz um debate sobre sistemas de comunicações para crianças que não vocalizam, entre eles, apontar, sinalizar e usar comunicação alternativa e aumentativa (CAA). Nesse contexto, o autor sugere pesquisas que comparem os sistemas e avaliem sua eficácia.

Nessa perspectiva, Sundberg (1993) fez uma comparação entre comunicação facilitada ${ }^{2}$, sistemas de apontar e língua de sinais. Ao debater uso da língua de sinais para crianças não verbais, o autor apresenta vantagens e desvantagens para o uso da ASL no ensino. As vantagens são: a) ser livre de um aparato ambiental pré-preparado, ou seja, assemelha-se à vocalização; b) a comunidade surda funciona como comunidade verbal; c) a imitação motora é mais provável do que a imitação vocal; d) pois facilita o uso de dicas físicas e verbais; e) a relação icônica dos sinais colabora para as dicas; f) a língua de sinais pode melhorar a fala; g) envolve resposta e discriminação mais simples; h) há 
correspondência ponto-a-ponto entre respostas; i) as línguas de sinais podem evitar o histórico aversivo emocional envolvendo a fala. As desvantagens são: a) o ouvinte que não sinaliza precisa ser treinado e modelado, necessitando de constante supervisão da comunidade verbal que utiliza os sinais; b) o treinador deve modelar respostas individuais. Ao comparar a fala, a comunicação facilitada, o sistema de apontar e a língua de sinais, esta última apresenta pontos fortes em todos os operantes verbais (mando, tato, intraverbal, autoclítico e receptivo), mas ponto entre fraco e mediano nos operantes do tipo código (textual e ditado), ficando atrás da fala. O autor conclui que, na falta da possibilidade de treino da fala, a língua de sinais seria a melhor alternativa para crianças não verbais.

McCarty (2004) faz uma análise funcional da linguagem escrita dos sinais e o sistema de notações (STOKOE, 2005/1960). O texto inicia com uma análise da Cultura Surda e o estabelecimento da ASL. Posteriormente, uma análise funcional sobre a ASL como comportamento verbal assemelha-se ao apresentado por Michael (1982). Segundo a autora, os surdos, por meio da ASL, poderiam emitir mando, tato, intraverbal e mimético (sinalizar o que foi sinalizado), porém, operantes verbais, como o textual, seriam um problema para a comunidade surda porque seria necessário estabelecer qual escrita seria utilizada para tais fins. Nesse caso, McCarty (2004) faz uma análise de duas formas de escrita da língua de sinais: A notação de Stokoe (2005/1960) e o sign writing de Valerie Sutton (1981). Consequentemente, esta análise funcional promove implicações para futuras pesquisas, entre elas, seria mais efetiva uma escrita de sinais ou da língua do país de origem (por exemplo, português escrito)? Ou quais os efeitos do ensino desse textual na vocalização ou aquisição da língua do país de origem? A autora conclui descrevendo estudos inovadores sobre a surdez e convidando pesquisadores analistas do comportamento para futuras pesquisas no tema.

O estudo de Greer e Speckman (2009) faz uma análise e integração da resposta de ouvinte e falante na teoria do desenvolvimento verbal. O contexto dos surdos é citado duas vezes. Primeiro, os autores apresentam os surdos como uma comunidade que adquire a leitura com compreensão tardiamente, em comparação com os ouvintes e atribui a causalidade à falta de retorno de componentes fonéticos auditivos. Posteriormente, os autores ratificam a falta do componente auditivo para melhor estabelecimento do repertório de ouvinte, apesar de analisar que a fala pode ser substituída pela sinalização enquanto estímulo, essa falta de ouvir ocasionaria o atraso da aquisição da leitura com compreensão. 
Por último, Borthwick-Duffy, Palmer e Lane (1996) abordam a diferença entre inclusão e diferenças individuais. A principal análise é feita sobre o tema da inclusão como acessibilidade para todos com a bandeira da igualdade e como este lema pode afetar algumas comunidades com particularidades individuais, por exemplo, a comunidade surda. No tópico sobre perdas sensoriais, os autores enfatizam que o surdo é o que menos necessita de intervenções em relação aos outros PAEE. Em contrapartida, a comunidade surda é a mais resistente à inclusão por considerar um entrave para o estabelecimento de uma Cultura e da Comunidade Surda, como também, de modelos surdos para inspiração dos novos. Os argumentos a favor da inclusão do surdo estão pautados na convivência com diferentes comunidades (ouvintes e outros do PAEE) e a diminuição do isolamento social, enquanto os defensores das escolas bilíngues se baseiam no fortalecimento cultural, especificidade do método de ensino para os surdos e especialização de profissionais no tema.

Os estudos empíricos foram divididos em dois subgrupos: Multiformes e Uniformes. $O$ grupo multiforme é formado por artigos no qual os participantes são variados, pois além dos participantes surdos, incluem participantes com desenvolvimento típico, TEA, Deficiência Intelectual, etc. Os estudos empíricos uniformes apresentam dados somente sobre participantes surdos.

Os artigos multiformes formaram $47,8 \%$ dos artigos empíricos $(n=11)$. Os estudos apresentavam pelo menos um participante surdo entre outros participantes do PAEE, como crianças com TEA (HAMMOND et al., 2011), deficiência intelectual (NEEF; IWATA; PAGE, 1980), deficiência física (SHORE et al., 1998), atraso no desenvolvimento (MUELLER; EDWARDS; TRAHANT, 2003), atraso na linguagem (WOLERY et al., 1993), desenvolvimento típico (BARNES; MCCULLAGH; KEENAN, 1990; MANN; BUSCHELL; MORRIS, 2010; ELIAS; GOYOS, 2013) e vários diagnósticos (MILLER et al., 2003; FRITZ et al., 2013; KURTZ et al., 2013).

Entrelaçando os dados das intervenções aplicadas nos estudos e tema de pesquisa, alguns dados apresentados são resultados desses estudos de grupos multiformes. Os resultados encontrados para a categoria Redução de comportamentos $(n=4)$ são todos formados por artigos do grupo multiforme, da mesma forma, os dados apresentados na categoria Saúde/Segurança $(\mathrm{n}=4)$ nos temas de pesquisa.

O estudo de Mueller, Edwards e Trahant (2003) teve como objetivo testar três opções de tratamento para comportamentos problemas: reforçamento não contingente (NCR), reforço diferencial de respostas alternativas (DRA) e reforçamento negativo diferencial para 
http://dx.doi.org/10.5902/1984686X65604

respostas alternativas (DNRA). Os autores observaram por análise funcional comportamentos problemas específicos para cada participante ( $n=3$, sendo 1 surdo). Após a aplicação dos três procedimentos com um delineamento de múltiplos elementos, os resultados apresentaram-se mais efetivos para as opções de (NCR) e (DRA). O participante surdo se comunicava por modulador de frequência (FM) e sinalização.

Hammond et al. (2011) verificaram o efeito da sinalização ou não sinalização em esquemas fixos momentâneos de reforço diferencial de outros comportamentos (DRO) em comportamentos problemas. Três participantes eram crianças com TEA e uma surda. Os autores realizaram uma análise funcional para identificação dos comportamentos problemas, a sinalização ocorria com a apresentação do item reforçador acima da cabeça do experimentador até a emissão de outro comportamento, e a contingência sem sinalização não a apresentação do item reforçador acima da cabeça do experimentador (o item ficava guardado). Os resultados são melhores para condições nas quais o (DRO) é apresentado sem sinalização (item ausente).

Fritz et al. (2013) apresentaram três objetivos: a) ilustrar um método de análise para identificar precursores de comportamentos; b) verificar quais reforçadores fazem a manutenção dos comportamentos problema; e c) testar se as análises foram corretas e se a introdução contínua do (NCR) seguida de (NCR + DRA) colabora na redução desses comportamentos. Foram selecionados 16 participantes para a pesquisa, sendo somente uma surda. O artigo foi dividido em 3 estudos, de acordo com os objetivos, e a participante surda esteve no Estudo I e no Estudo III, ou seja, com a participante surda ocorreu a análise funcional dos mantenedores do comportamento problema e a intervenção por (NCR) e (NCR + DRA). Os resultados gerais apresentam uma efetividade para os três objetivos e para a criança surda também. Os autores ratificam a efetividade do NCR e que a adição do DRA colaborou para mais emissões de comportamentos adequados.

Ainda nessa perspectiva da redução de comportamentos problemas, Kurtz et al. (2013) procuraram avaliar a efetividade de análises funcionais feitas por cuidadores em comparação com a análise realizada pela equipe de profissionais. O estudo teve 52 participantes em formato de estudos de casos, sendo identificado 3 com perdas sensoriais, mas sem detalhes de quantos surdos. O método consistiu na análise funcional de comportamentos problemas e posteriormente foi conduzido o treino dos cuidadores para realização da análise funcional e aplicação de intervenções para redução do 
http://dx.doi.org/10.5902/1984686X65604

comportamento problema. Os resultados gerais apresentam uma maior efetividade por parte dos cuidadores para identificar comportamentos problemas nos participantes.

Shore et al. (1998) não focam nos comportamentos problemas, mas tem como tema Saúde/Segurança, semelhante aos artigos multiformes citados anteriormente. Os autores estabeleceram contingências para fortalecer a ingestão de alimentos com texturas mais sólidas em pacientes com dificuldades na alimentação. O estudo teve 4 participantes, sendo uma participante surda. O método consistiu no esvanecimento da textura dos alimentos até atingir a textura programada. A conclusão dos autores estabelece uma variação de procedimento, uma soma entre controle da textura, reforçamento da aceitação e o engolir do alimento, como também, a extinção da rejeição e comportamentos de expulsão do alimento. Dessa forma, todos os participantes conseguiram ao final comer alimentos com texturas mais densas.

A outra categoria com artigos multiformes são os temas envolvendo Educação (Comportamento Acadêmico ou Comportamento de Ensinar), envolvendo intervenções com aquisição ou fortalecimento de repertório e controle de estímulos. Neef, Iwata e Page (1980) avaliaram o efeito do treino interpessoal e reforçamento de alta densidade na modelagem de desempenhos acadêmicos. $O$ estudo teve 3 participantes, sendo um surdo e tinha como variável dependente a soletração de palavras selecionadas pelos experimentadores em um delineamento de múltiplos elementos, avaliaram a linha de base e analisaram a aplicação alternada de treinamento interpessoal e reforçamento de alta densidade. Ao comparar os resultados, os autores concluíram que o treinamento interpessoal foi mais efetivo que o reforçamento de alta densidade. Os experimentadores utilizaram línguas de sinais para instruir o participante surdo e a datilologia como resposta.

Já o estudo de Wolery et al. (1993) teve como objetivo comparar o efeito de dois procedimentos de apresentação de feedback instrutivo durante o treino direto em crianças pré-escolares. Dos 5 participantes do experimento, apenas 1 era surdo e os resultados não apresentaram diferença nos dois procedimentos. O estudo de Miller et al. (2003) avaliou o efeito de círculos de amizade na interação social de participantes do PAEE e seus pares na escola. O método consistiu na observação de vários contextos escolares (aula, lanche e aulas fora da sala) e verificou a porcentagem de comportamentos apropriados socialmente, inapropriados socialmente e sem interação social em 3 participantes (sendo um surdo). A aplicação do círculo de amizade consistia no momento de grupo no qual o experimentador intervia nas interações sociais e orientava os profissionais como intervir nessas 
circunstâncias. Os resultados apresentaram um aumento nas interações sociais apropriadas e uma redução dos comportamentos inapropriados e sem interação social, mais ainda, o procedimento foi efetivo na manutenção dessa interação após as fases de intervenção.

Mann, Bushell e Morris (2010) utilizaram o procedimento de cobrir-copiar-comparar (cover-copy-compare - CCC) em conjunto com (sounding out - SO) em cinco crianças préescolares (sendo um participante surdo). Os participantes deveriam soletrar as palavras em condições alternadas entre (CCC) e $(C C C+S O)$, depois o pós-teste era aplicado. Os resultados do estudo apresentam efetividade na presença do (SO) e manutenção do repertório após a aplicação do procedimento.

Por último, os estudos multiformes apresentaram dois estudos com tema baseado em controle de estímulos. Barnes, McCullagh e Keenan (1990) tiveram como objetivo analisar os resultados de três grupos de 2 crianças (sendo 4 crianças surdas) no desempenho de tarefas de discriminação condicional. O grupo 1 era constituído de crianças ouvintes, 0 grupo 2 de crianças surdas com idade verbal acima de 2 anos, e o grupo 3 com crianças surdas com idade verbal abaixo de 2 anos. O procedimento consistia no ensino e generalização de repertórios como tato e relações condicionais entre palavra-objeto e objeto-palavra. Os resultados apresentaram indícios da formação de classes de estímulos equivalentes nos grupos 1 e 2, o grupo 3 também apresentou, mas teve uma participante que precisou de treinos adicionais.

Na mesma perspectiva de controle de estímulos, o estudo de Elias e Goyos (2013) avaliou se o ensino direto de respostas miméticas (sinalizar diante de vídeos com sinalizações - equivalente ao ecoico) antes de tarefas de escolha de acordo com o modelo (MTS) e o uso dessas respostas miméticas como respostas de observação diferenciadas para o estabelecimento de classes (videoclipes - A, figuras - B e palavras impressas - C), para a emergência de tatos sinalizados não ensinados e respostas textuais. $O$ experimento foi realizado com 5 crianças (3 ouvintes e 2 surdas). Os resultados apresentam desempenhos altos para a imitação dos sinais diante do vídeo (mimético), nos testes de equivalência e a emergência de tatos sinalizados e respostas textuais.

Os estudos empíricos uniformes concentram-se, na sua maioria, no tema Comportamento Acadêmico e Comportamento de Ensinar. Osborne (1969) teve como objetivo utilizar um procedimento de reforçamento de um comportamento acadêmico (sentar na cadeira e prestar atenção na aula) para seis crianças surdas. Foi utilizado o delineamento de sujeito único do tipo ABA para testar a efetividade do reforçador. Os resultados se 
apresentaram favoráveis, aumentando o desempenho dos alunos em sala de aula e promovendo um método mais econômico de intervenção comportamental para escolas especializadas em surdos. Este estudo é pioneiro na utilização de princípios comportamentais na comunidade surda, sendo importante a participação do autor J. Grayson Osborne (OSBORNE, 1969; OSBORNE; WAGEMAN, 1969; OSBORNE; GATCH, 1989) para a relação da Análise do Comportamento e sua aplicabilidade para a comunidade surda.

Craig e Holland (1970) tiveram como objetivo fortalecer a atenção visual dos alunos surdos em direção ao professor em sala de aula. Por meio de 3 experimentos, os autores avaliaram o efeito de diferentes reforçadores numa sala com alunos surdos (Experimento I) e replicaram com outra sala de alunos surdos (Experimento II) e com uma nova sala com controle experimental do próprio professor (Experimento III). Os resultados apresentam um aumento dos comportamentos classificados como atenção ao professor e a diminuição ou eliminação dos comportamentos concorrentes. Importante ressaltar que, um dos estímulos discriminativos utilizado no experimento era a atenção ao lábio, ou seja, treino da leitura labial.

Bennett e Ling (1972) avaliaram a generalização após o treino de sentenças, para o uso na ordem correta das palavras "the" e "is" em uma criança surda. Após o treino de duas sentenças como modelo (The girl is swimming e The boy is running), a criança respondeu a testes com outras 15 sentenças para observar a efetividade do experimento e os resultados apresentados foram favoráveis à aplicação de princípios comportamentais para este comportamento de construção de sentenças.

Wilson e McReynolds (1973) verificaram o efeito do uso de reforçamento diferencial de altas taxas ( $\mathrm{DRH}$, do inglês differential reinforcement of high rates) e utilização de vibração no pulso para fortalecimento da leitura oral em 6 crianças surdas (4 no grupo experimental e 2 no grupo controle). Os participantes do grupo experimental aumentaram a leitura oral no ensino e teste, e diminuíram o tempo de resposta entre apresentação do estímulo e o início da emissão da resposta em relação ao grupo controle, sugerindo a eficácia do procedimento.

Na mesma perspectiva, Bennett (1974) aplica o princípio operante para o treino de fala em 2 crianças surdas. O repertório definido é o fonema do inglês /f/ e /sh/ para treino no início das palavras, posteriormente, testado no início de novas palavras e no final de novas palavras. Os resultados foram satisfatórios para o ensino e generalização do 
repertório e os autores concluíram o estudo propondo a imitação baseada no condicionamento operante para melhoria da fala de crianças com deficiência auditiva.

Smeets e Striefel (1975) tiveram como objetivo testar quatro condições de reforçamento no desempenho de 52 surdos nas respostas diante do teste da Matriz Progressiva de Raven: 1) reforçamento ao fim da sessão; 2) NCR; 3) reforçamento atrasado; e 4) reforçamento imediato. Os autores utilizaram língua de sinais para instruir ou fornecer feedbacks aos participantes e o método consistiu em delineamento com pré e pósteste. Os resultados apresentam a condição do reforço imediato como o mais efetivo para o ensino e teste dos desempenhos na Matriz Progressiva de Raven.

Houten e Nau (1980) procuraram verificar o efeito de dois esquemas de reforçamento, razão fixa e razão variável, na atenção de 5 alunos surdos em sala de aula. O método consistiu em um delineamento de reversão ABA com os dois esquemas de razão. Os resultados apresentados mostram um aumento no repertório de atenção dos alunos na aula, com desempenho maior no esquema de razão variável. Os autores enfatizam a necessidade de atenção aos alunos para o lábio do professor para realizar a leitura labial.

De uma perspectiva diferente, Ward, Johnson e Konukman (1998) verificaram o efeito do treino de professores de educação física para estabelecimento de três repertórios: transições (mudanças do aluno de um espaço para o outro), introdução da lição e apresentação da tarefa. Uma linha de base entre participantes verificou o efeito do procedimento. Os resultados apresentaram a efetividade do procedimento para os três repertórios com todos os participantes. A participante surda teve o acompanhamento de intérprete em ASL para o experimento, nas instruções e conduções das tarefas.

O estudo de Golfeto e Souza (2015) verificou o efeito do ensino do repertório de ouvinte e treino de ecoico na produção oral de sentenças por três crianças com implante coclear. Utilizando uma linha de base múltipla com matrizes das sentenças, os autores verificaram o aumento e a generalização do repertório dos participantes, do estabelecimento do repertório de ouvinte até a generalização da construção de sentenças baseadas na matriz.

Os outros estudos empíricos com grupos uniformes (somente participantes surdos) focaram em comportamentos sociais dos surdos. Rasing e Duker (1992) treinaram três habilidades sociais: esperar a vez, iniciar a interação social e manter a interação social em 9 crianças com surdez. Os resultados apresentam um aumento de comportamentos apropriados e uma redução de comportamentos inapropriados para a interação social; os 
alunos foram instruídos tanto oralmente, quanto por um treinamento manual. Posteriormente, Rasing (1993) replicou Rasing e Duker (1992), mas com 20 alunos surdos e os resultados reproduziram a eficácia do procedimento, as instruções foram repassadas com uma combinação de oralização, datilologia e escrita. Por último, Ducharme e Holborn (1997) treinaram cinco crianças surdas em várias categorias de habilidades sociais (organização da brincadeira, compartilhamento e cooperação), junto com comportamento de preparação, treino e manutenção de comportamentos na brincadeira dos professores. Uma linha de base múltipla avaliou a condição de dois tipos de tratamento e a generalização. Um tratamento usava instruções, modelagem, dicas e reforçamento; o outro usava as mesmas configurações com a utilização de múltiplos exemplares. A conclusão do estudo aponta para uma eficácia para o ensino de habilidades sociais para ambos os tratamentos, mas uma eficácia maior para o segundo (múltiplos exemplares) nos resultados de generalização.

\section{Análise da posição filosófica educacional da Surdez dos artigos}

A Figura 5 apresenta os artigos divididos de acordo com a categoria da filosofia educacional da história da surdez. Os artigos foram classificados em oralista, comunicação total e bilinguista. Alguns estudos não apresentaram definição, portanto, foram definidas como "não definido" e "não definido com sinais", este último incluindo estudos com uso de sinais, mas sem definição específica de qual escola educacional foi adotado no estudo.

Figura 5 - Quantidade de artigos de acordo com a filosofia educacional adotada

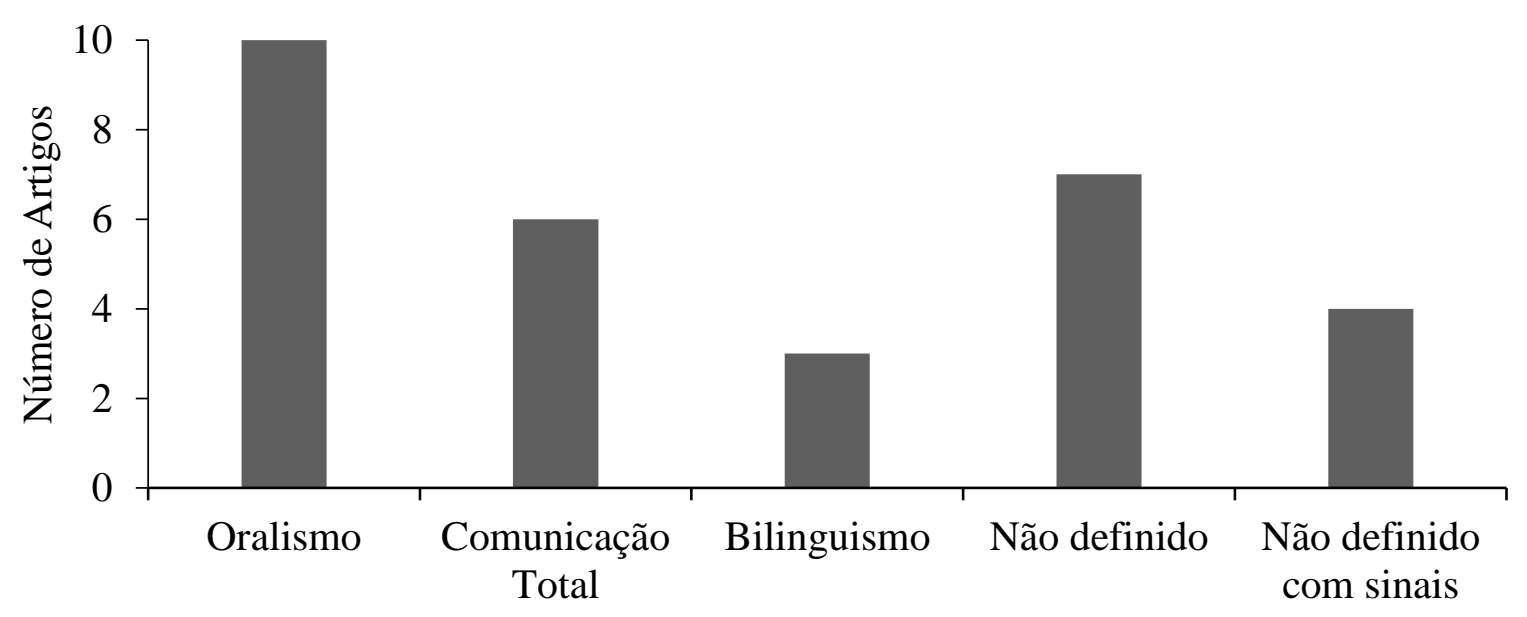

Filosofia Educacional

Fonte: Autoria própria (2018). 
A categoria Oralismo abarca a maior concentração de artigos $(n=10)$, seguido por artigos não definidos $(n=7)$, comunicação total $(n=6)$, não definido com sinais $(n=4)$, e por último, o bilinguismo $(n=3)$. Uma análise dos paradigmas sobre a concepção de surdez, a clínica-patológica e a socioantropológica, pode inferir qual o direcionamento tomado pela maior parte dos trabalhos da Análise do Comportamento sobre surdez. A visão clínicapatológica tem uma desvalorização dos sinais e promoção de articulação da fala (mesmo com AASI e Implante Coclear), enquanto a visão socioantropológica valoriza a língua de sinais como identidade cultural do surdo e sua voz no mundo. Dessa forma, o oralismo e a comunicação total somam 16 artigos (53\%), os artigos não definidos atingiram 7 artigos (23\%), enquanto os estudos bilíngues e não definidos com sinais atingiram 7 artigos (23\%).

A Figura 6 apresenta dados cumulativos dos artigos em cada abordagem da filosofia educacional por ano. O Oralismo apresenta uma frequência acumulada maior ao decorrer dos anos, mantendo publicações ao longo dos anos e sendo a abordagem com maior quantidade de artigos. Os estudos sobre Comunicação Total emergem a partir dos anos 70 e mantém sua produção, estabelecendo a segunda colocação dos artigos produzidos sobre o tema. Em relação ao bilinguismo, os estudos emergem a partir dos anos $90 \mathrm{e}$ mantém uma produção menor em relação ao Oralismo e Comunicação Total. Essas emergências das abordagens ocorrem paralelamente ao desfecho histórico das filosofias educacionais na surdez (CAPOVILLA, 2000). O surgimento da Comunicação Total é estabelecido nos anos 70 e do Bilinguismo nos anos 90, ou seja, a Análise do Comportamento apresenta registros na sua produção internacional de reflexos de agências de controle educacional e filosófico sobre o tema, apresentando estudos sobre as três abordagens.

Em relação aos estudos não definidos ou não definidos com uso de sinais, os dados apresentam uma frequência acumulada maior na categoria não definidos. Este fato pode indicar um foco maior da produção na Análise do Comportamento em temas e problemas de pesquisa da área, somado à generalização para outros públicos-alvo. Essa análise seria reforçada com a presença de estudos utilizando Língua de Sinais, mas sem reflexões e debates teóricos sobre abordagens educacionais. A constante análise de estudos sobre o tema e a análise de estudos experimentais em revistas sobre Surdez e Deficiência Auditiva podem colaborar para aumentar o panorama, ratificar ou retificar essas inferências. 
http://dx.doi.org/10.5902/1984686X65604

Figura 6 - Gráfico cumulativo dos artigos de acordo com a filosofia educacional por ano de publicação

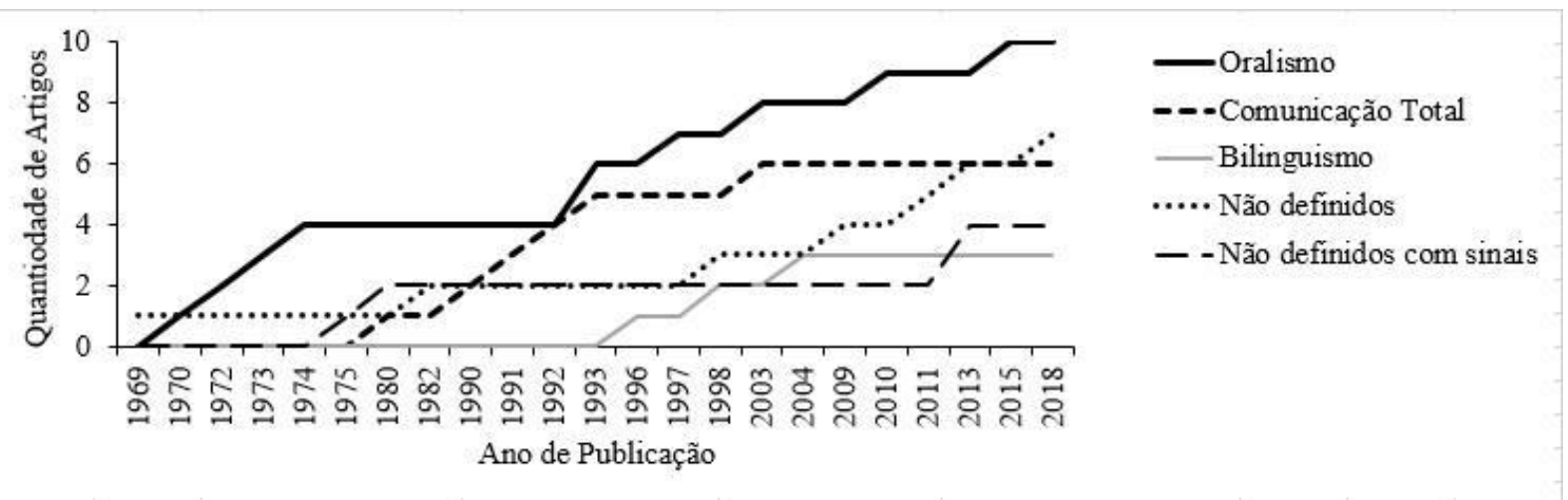

Fonte: Autoria própria (2018).

Esses dados apresentam um posicionamento da Análise do Comportamento próximo com a visão clínica-patológica da surdez, ora priorizando o treino da fala em detrimento da língua de sinais, ora se ausentando do debate sem definir qual postura filosófica educacional adotada. Aprofundando a análise desses dados, Lacerda (1998) afirma que a utilização da língua de sinais no país não implica uma filosofia bilíngue, por exemplo, os Estados Unidos são reconhecidos pelos estudos e valorização da ASL, entretanto, a filosofia educacional predominante na época era a Comunicação Total (LACERDA, 1998). Consequentemente, os artigos não definidos com sinais podem não representar uma visão socioantropológica. Nesta perspectiva, somente os três estudos bilíngues (BORTHWICKDUFFY; PALMER; LANE, 1996; WARD; JOHNSON; KONUKMAN, 1998; MCCARTY, 2004) seriam essencialmente antropológicos e apresentariam o debate da língua de sinais como materna para o surdo.

Os dados de Santos e Elias (2019) apresentam raciocínio semelhante, os grupos divididos em implante coclear e uso de sinais corroboram tal hipótese. Os estudos de implante coclear seguem uma filosofia baseada no oralismo, mais especificamente, o aurioral. Os estudos com uso de sinais não têm definição nenhuma da escola educacional, somente um estudo se definiu como Comunicação Total. Os estudos sobre uso de sinais no ensino de matemática ou português utilizam o paradigma da equivalência de estímulos (SIDMAN, 1994).

Em resumo, a Análise do Comportamento, ao ser confrontada com posições filosóficas da história da surdez, se posiciona como oralista/aurioral ou se isenta do debate, apesar do uso dos sinais. Os estudos com oralismo, comunicação total, não definidos e não definidos com sinais têm $90 \%$ dos artigos apresentados nessa revisão, enquanto o bilinguismo tem a menor parcela. Uma vez somados os dados do Santos e Elias (2019), é 
http://dx.doi.org/10.5902/1984686X65604

possível afirmar que a Análise do Comportamento em âmbito nacional e internacional não tem uma defesa bilinguista de ensino para surdos e fraco posicionamento sobre uma visão sócio antropológica do tema.

\section{Considerações finais}

O objetivo deste capítulo foi analisar artigos sobre surdez e deficiência auditiva em periódicos internacionais de Análise do Comportamento entre os anos de 1968 a 2018. Os periódicos internacionais foram recomendados pela $\mathrm{ABAl}$ e pesquisados com termos do público surdo/deficiência auditiva nos campos de busca da revista. Os estudos encontrados sobre surdez/deficiência auditiva colaboram para um quadro sobre um público pouco encontrado na literatura da Análise do Comportamento (KAZDIN, 1982; NICOLINO; ZANOTTO, 2010, 2011; CEDRO; PASSARELLI; HUZIWARA, 2014; ESTEVES; LUCCHESI; ALMEIDA-VERDU, 2014; CRAVO et al., 2018).

As conclusões não apresentam dados significativos sobre o ano de produção dos artigos. Os estudos têm uma prevalência por serem aplicados, experimentais, com o agente de mudança em geral sendo o próprio experimentador e o ambiente de coleta em geral é uma escola especial ou escola regular. Estes dados assemelham-se ao da literatura (ver SANTOS; ELIAS, 2019; NICOLINO; ZANOTTO, 2010,2011). Um dado novo apresentado pelo estudo é a quantidade de estudos teóricos com a presença de explicações ou dentro da temática sobre surdez/deficiência auditiva. Santos e Elias (2019) e Nicolino e Zanotto (2011) apresentam dados aplicados na sua maioria e Nicolino e Zanotto (2010) analisam artigos de uma revista focada em estudos aplicados (JABA). O presente estudo, além de apresentar artigos teóricos descrevendo aspectos conceituais da língua de sinais como comportamento verbal (MICHAEL, 1982; SUNDBERG, 1991, 1993), também pode colaborar para futuras pesquisas analisando aspectos conceituais, filosóficos e sociais da comunidade surda, do uso da língua de sinais e dos debates educacionais entre Oralismo, Comunicação Total e Bilinguismo.

As respostas medidas variaram bastante entre os estudos, subdividindo os estudos empíricos em grupos uniforme ou multiforme. Os estudos multiformes apresentaram proximidade com intervenções baseadas na redução de respostas e com temas como comportamento acadêmico e saúde/segurança. Os estudos uniformes focaram mais na aquisição e fortalecimento de repertórios acadêmicos e de ensino. A importância desses dados apresenta validade externa na aplicabilidade dos princípios da Análise do 
Comportamento, em ambos os subgrupos. Os dados sobre a resposta medida diferenciam dos dados apresentados por Santos e Elias (2019). Enquanto neste capítulo ocorre uma variabilidade de respostas medidas, Santos e Elias (2019) apresentam dados sobre comportamento verbal e simbólico. Esses dados podem ter sido diferenciados pelo aspecto geográfico dos estudos, porém estudos realizando análises de outras revistas, locais de pesquisa ou revisando os dados de vários estudos poderiam contribuir para um panorama mais refinado das variáveis influenciadoras do modelo de pesquisa. Outro caminho seria buscar estudos sobre Análise do Comportamento em revistas sobre Educação Especial.

Os três grupos de estudos (teórico, multiforme e uniforme) foram analisados segundo os crivos das filosofias educacionais da história da surdez (CAPOVILLA, 2000). Neste caso, os estudos da Análise do Comportamento se aproximam de filosofias oralistas ou não definem a postura filosófica. Os estudos focados em uma proposta bilíngue ou que debatem o tema tiveram pouca representatividade nos dados.

Ao analisarmos a relação da Análise do Comportamento com a Comunidade Surda, podemos inferir uma efetividade dos procedimentos, delineamentos e princípios comportamentais adquiridos na história da área. Entretanto, a abordagem não se define politicamente sobre o que seria relevante para a comunidade surda: oralizar, todas as técnicas ou língua de sinais. Futuras pesquisas podem valorizar as línguas de sinais como comunicação e Cultura da Comunidade Surda, realizando análises funcionais baseadas na junção entre relevância acadêmica e política do PAEE (mais especificamente, aquelas voltadas aos surdos).

As lacunas não preenchidas por esse estudo podem estar na amplitude do tema, apesar das revistas pesquisadas abordarem a Análise do Comportamento em âmbito aplicado e internacional, há possibilidades de pesquisadores da área publicarem em revistas de outros campos do conhecimento, mesmo com a temática da análise do comportamento. Futuras revisões podem ampliar o escopo desta análise da relação entre Análise do Comportamento e Surdez.

\section{Referências}

AGUIAR, Cecília. et al. Desenhos de investigação de sujeito único em educação especial. Análise Psicológica. Lisboa, 1 (29), p. 167-178 (2011). Disponível em: http://www.scielo.mec.pt/pdf/aps/v29n1/v29n1a11.pdf. Acesso em: 14 abr. 2021. Doi: 10.14417/ap.46. 
BALLARD, Keith D. The limitations of Behavioural Approaches to Teaching: Some implications for special education. The Exceptional Child, 34 (3), 197-212, (1987). Disponível em:

https://www.tandfonline.com/doi/abs/10.1080/0156655870340305?journalCode=cijd19. Acesso em: 14 abr. 2021. Doi: 10.1080/0156655870340305.

BARBOSA, Diego Grasel. et al. Análise epistemológica de teses e dissertações de dois programas de pós-graduação stricto sensu da educação física sobre pessoas com deficiência. Revista Brasileira de Educação Especial. Marília, 22(2), 285-298. (2016). Disponível em: https://www.scielo.br/pdf/rbee/v22n2/1413-6538-rbee-22-02-0285.pdf. Acesso em: 14 abr. 2021. Doi: 10.1590/S1413-65382216000200010.

BARNES, Dermot; MCCULLAGH, Paul. D.; KEENAN, Michael. Equivalence Class Formation in non-hearing impaired children and hearing impaired children. The Analysis of Verbal Behavior. Ireland, 8, 19-30. (1990). Disponível em: https://www.ncbi.nlm.nih.gov/pmc/articles/PMC2748610/pdf/anverbbehav00037-0021.pdf. Acesso em: 14 abr. 2021.

BAUM, William M. Relativity in hearing and stimulus discrimination. Perspective in Behavior Science, 1-7. (2018). Disponível em:

https://link.springer.com/article/10.1007/s40614-018-0161-x\#citeas. Acesso em 14 abr. 2021. Doi: 10.1007/s40614-018-0161-x.

BENNETT, Clinton W. Articulation training of two hearing-impaired girls. Journal of Applied Behavior Analysis, 7(3), 439-445. (1974). Disponível em: https://www.ncbi.nlm.nih.gov/pmc/articles/PMC1311989/pdf/jaba00061-0085.pdf. Acesso em: 14 abr. 2021. Doi: 10.1901/jaba.1974.7-439.

BENNETT, Clinton W.; LING, Daniel. Teaching a complex verbal response to a hearingimpaired girl. Journal of Applied Behavior Analysis, 5(3), 321-327. (1972). Disponível em: https://www.ncbi.nlm.nih.gov/pubmed/16795354. Acesso em: 14 abr. 2021. Doi: 10.1901/jabá.1972.5-321

BORTHWICK-DUFFY, Sharon A.; PALMER, David. S; LANE, Kathleen. One size doesn't fit all: full inclusion and individual differences. Journal of Behavioral Education, 6(3), 311-329. (1996). Disponível em: http://www.jstor.org/stable/41824134. Acesso em: 14 abr. 2021.

BRASIL. Ministério da Educação. Lei n. 9.394, de 20 de dezembro de 1996. Estabelece as diretrizes e bases da educação nacional. Brasília, DF (1996). Disponível em: http://www.planalto.gov.br/ccivil_03/leis/19394.htm.

BRAUN, Patricia. Uma intervenção colaborativa sobre os processos de ensino e aprendizagem do aluno com deficiência mental (Tese de doutorado). UERJ, Rio de Janeiro. (2012)

CAPOVILLA, Fernando Cesar. et al. Dicionário de Língua de Sinais do Brasil: A Libras em suas Mãos (1ํㅡㄹ ed). São Paulo: Edusp . (2017). 
CAPOVILLA, Fernando Cesar. Filosofias educacionais em relação ao surdo: Do oralismo à Comunicação Total ao Bilinguismo. Revista Brasileira de Educação Especial, 6 (1), 99-116. (2000). Disponível em: https://abpee.net/pdf/artigos/art-6-6.pdf. Acesso em: 14 abr. 2021.

CARRARA, Kester. Uma ciência sobre "coisa" alguma: relações funcionais, comportamento e cultura (1ํa ed.). São Paulo: Unesp. (2015).

CEDRO, Átila Moreira; PASSARELLI, Anna Christina. P. M.; HUZIWARA, Edson Massaiuky. Um panorama de estudos nacionais sobre a aquisição de nomeação em procedimentos com equivalência de estímulos e usuários de implante coclear. Revista Brasileira de Análise do Comportamento, 10 (1), 84-96. (2014). Disponível em: https://periodicos.ufpa.br/index.php/rebac/article/view/2552/2757. Acesso em: 14 abr. 2021. Doi: 10.18542/rebac.v10i1.2552.

CRAIG, Hellen B.; HOLLAND, Audrey L. Reinforcement of visual attending in classrooms for deaf children. Journal of Applied Behavior Analysis, 3(2), 97-109. (1970). Disponível em: https://www.ncbi.nlm.nih.gov/pmc/articles/PMC1311099/pdf/jaba00076-0023.pdf. Acesso em: 14 abr. 2021. Doi: 10.1901/jaba.1970.3-97.

CRAVO, Felipe Augusto Monteiro. et al. Teaching of expressive repertoire to children who are users of cochlear implants: A literature review. Revista Brasileira de Educação Especial. Marília, 24 (4), 545-560. (2018). Disponível em:

http://www.scielo.br/pdf/rbee/v24n4/en_1413-6538-rbee-24-04-0551.pdf. Acesso em: 14 abr. 2021. Doi: 10.1590/s1413-65382418000500006

DUCHARME, Dell E.; HOLBORN, Stephen W. Programming generalizations of social skill in preschool children with hearing impairments. Journal of Applied Behavior Analysis, 30(4), 639-651. (1997). Disponível em:

https://www.ncbi.nlm.nih.gov/pmc/articles/PMC1284081/pdf/9433789.pdf. Acesso em: 14 abr. 2021. Doi: 10.1901/jaba.1997.30-639.

ELIAS, Nassim Chamel; GOYOS, Celso. Mimetic relations as matching-to-sample observing response and the emergence of speaker relations in children with and without hearing impairments. The Psychological Record, 63, 131-140. (2013). Disponível em: https://link.springer.com/article/10.11133/j.tpr.2013.63.1.010. Acesso em: 14 abr. 2021. Doi: 10.11133/j.tpr.2013.63.1.010.

ESTEVES, Raquel Chaguri; LUCCHESI, Fernando Del Mando; ALMEIDA-VERDU, Ana Claudia Moreira Almeida. Ensino de ecoico, tato e mando: uma revisão bibliográfica dos artigos do Journal of Applied Behavior Analysis (JABA). Revista Brasileira de Terapia Comportamental e Cognitiva, 16 (2), 109-124. (2014). Disponível em: http://www.usp.br/rbtcc/index.php/RBTCC/article/view/694/414. Acesso em 14 de abr. 2021. Doi: $10.31505 /$ rbtcc.v16i2.694.

FERNANDES, Fernanda Dreux Miranda; AMATO, Cibelle Albuquerque de la Higuera. Análise do Comportamento Aplicada e Distúrbio do Espectro do Autismo: revisão de literatura. CoDas, 25 (3), 289-296. (2013). Disponível em:

http://www.scielo.br/pdf/codas/v25n3/16.pdf Acesso em 14 de abr. 2021. Doi:

10.1590/S2317-17822013000300016. 
FRITZ, Jennifer N. et al. Experimental analysis of precursors to severe problem. Journal of Applied Behavior Analysis, 46(1), 101-129. (2013). Disponível em https://www.ncbi.nlm.nih.gov/pubmed/24114089. Acesso em: 14 ab. 2021. Doi: 10.1002/jaba.27.

GAMBOA, Sílvio Sánchez. Epistemologia da Pesquisa em Educação (Tese de doutorado). UNICAMP: Campinas. (1998).

GAST, David L. Single Subject Research Methodology in Behavioral Sciences. New York: Routeledge. (2010).

GLAT, Rosana; OMOTE, Sadao; PLETSCH, Márcia Denise. Análise crítica da produção do conhecimento em educação especial. In S. Omote, A. A. S., \& Chacon, M. C. M. (Orgs.), Ciência e Conhecimento em Educação Especial (pp. 25-44). São Carlos: Marquezine \& Manzini. (2014).

GLAT, Rosana; PLETSCH, Márcia Denise. O método de história de vida em pesquisas sobre auto-percepção de pessoas com necessidades educativas especiais. Revista Educação Especial, 22(34), 139-154. (2009). Disponível em:

file://C:/Users/jose/Downloads/268-921-1-PB.pdf. Acesso em 14 abr. 2021. Doi: 10.5902/1984686X.

GOLFETO, Raquel M.; SOUZA, Deisy. G de. Sentence production after listener and echoic training by prelingual deaf children with cochlear implants. Journal of Applied Behavior Analysis, 48(2), 363-375. (2015). Disponível em:

https://www.ncbi.nlm.nih.gov/pubmed/25916494. Acesso em: 15 abr.2021 Doi: 0.1002/jaba.197.

GOULART, Paulo; ASSIS, Grauben José Alves de. Estudos sobre autismo em análise do comportamento: aspectos metodológicos. Revista Brasileira de Terapia Comportamental e Cognitiva. São Paulo, 4(2), 151-165. (2002). Disponível em:

http://pepsic.bvsalud.org/scielo.php?script=sci_arttext\&pid=S1517-55452002000200007. Acesso em: 15 abr. 2021.

GREER, R. Douglas.; SPECKMAN, Jeanne Marie. The integration of speaker and listener responses: A theory of verbal development. The Psychological Record, 59, 449-488. (2009). Disponível em: https://link.springer.com/article/10.1007\%2FBF03395674. Acesso em: 15 abr. 2021. Doi: 10.1007/BF03395674.

GUERRA, Bárbara Trevizan; ALMEIDA-VERDU, Ana Claudia Moreira Almeida. Ensino de operantes verbais em pessoas com transtorno do espectro autista no The Analysis of Verbal Behavior: revisão sistemática. Revista Brasileira de Terapia Comportamental e Cognitiva, 18(2), 73-85. (2016). Disponível em:

http://www.usp.br/rbtcc/index.php/RBTCC/article/view/884/480. Acesso em: 15 de abr. 2021. Doi: 10.31505/rbtcc.v18i2.884.

HAMMOND, Jennifer L. et al. Evaluation of fixed momentary DRO schedules under signaled and unsignaled arrangements. Journal of Applied Behavior Analysis, 44(1), 69-81. (2011) Disponível em: https://www.ncbi.nlm.nih.gov/pmc/articles/PMC3050476/pdf/jaba-4401-69.pdf. Acesso em: 15 de abr. 2021. Doi: 10.1901/jaba.2011.44-69. 
HORNER, Robert. H. Review of Behavior Analysis in Developmental Disabilities 19681993 (3 594. (1997). Disponível em: https://onlinelibrary.wiley.com/doi/epdf/10.1901/jaba.1997.30591. Acesso em: 15 de abr. 2021. Doi: 10.1901/jaba.1997.30-591

HORNER, Robert. H.et al. The use of single-subject research to identify evidence-based practice in special education. Exceptional Children, 71 (2), 165-179. (2005). Disponível em: https://pdfs.semanticscholar.org/0b93/f8ef99ddd2582aa51a948304836fd8ca0578.pdf. Acesso em 15 abr. 2021. Doi: 10.1177/001440290507100203

HOUTEN, Ron Van; NAU, Paul A. A comparison of the effects of fixed and variable ratio schedules of reinforcement on the behavior of deaf children. Journal of Applied Behavior Analysis, 13(1), 13-21. (1980) Disponível em:

https://www.ncbi.nlm.nih.gov/pmc/articles/PMC1308102/pdf/jaba00047-0015.pdf. Acesso em 15 abr. 2021. Doi: 10.1901/jaba.1980.13-13

KAZDIN, Alan E. Single-Case research design: Methods for Clinical and Applied Settings. New York: Oxford University Press. (1982).

KURTZ, Patricia F. et al. Caregiver and staff conducted functional analysis outcomes: A summary of 52 cases. Journal Applied Behavior Analysis, 46(4), 738-749. (2013). Disponível em: https://www.ncbi.nlm.nih.gov/pubmed/24114788. Acesso em 15 abr. 2021. Doi: $10.1002 / j a b a .87$

LACERDA, Cristina B. F. de. Um pouco da história das diferentes abordagens da educação dos surdos. Cadernos CEDES, 19 (46), 68-80. (1998). Disponível em: https://www.aedi.ufpa.br/parfor/letras/images/documentos/ativ1_2014/maraba/maraba201 0_2/Ingua\%20bras\%20de\%20sinais\%20i_profa.\%20luana_educao\%20dos\%20surdos.pdf . Acesso em 15 abr. 2021. Doi: 10.1590/S0101-32621998000300007.

MANN, Tracie. B.; BUSCHELL, Don Jr.; MORRIS, Edward K. Use of sounding out to improve spelling in young children. Journal of Applied Behavior Analysis, 43(1), 89-93. (2010). Disponível em: https://www.ncbi.nlm.nih.gov/pmc/articles/PMC2831455/pdf/jaba43-01-89.pdf. Acesso em 15 abr. 2021. Doi: 10.1901/jaba.2010.43-89

MANZINI, Eduardo José; DELIBERATO, Débora. Recursos para comunicação alternativa. Brasília: MEC. (2004).

MARQUES, Luciana Pacheco. et al. Analisando as pesquisas em Educação Especial no Brasil. Pesquisas em Educação Especial no Brasil, 14 (2), 251-272. (2008). Disponível em: http://www.scielo.br/pdf/rbee/v14n2/08.pdf. Acesso em: 15 abr. 2021. Doi: $10.1590 /$ S1413-65382008000200008.

MARTONE, Maria Carolina Corrêa; SANTOS-CARVALHO, Larissa Helena Zani. Uma revisão de artigos publicados no Journal of Applied Behavior Analysis (JABA) sobre Comportamento Verbal e autismo entre 2008 e 2012. Perspectivas em Análise do Comportamento, 3 (2), 73-86. (2012). Disponível em: http://pepsic.bvsalud.org/pdf/pac/v3n2/v3n2a01.pdf. Acesso em: 15 abr. 2021. 
MCCARTY, Amy. M. Notation systems for Reading and writing sign language. The Analysis of Verbal Behavior, 20, 129-134. (2004) Disponível em:

https://www.ncbi.nlm.nih.gov/pmc/articles/PMC2755430/pdf/anverbbehav00025-0131.pdf. Acesso em 15 abr. 2021. Doi: 10.1007/bf03392999.

MICHAEL, Jack. Skinner's Elementary Verbal Relations: Some New Categories. The Analysis of Verbal Behavior, 1, 1-3. (1982) Disponível em:

https://www.ncbi.nlm.nih.gov/pmc/articles/PMC2748435/pdf/anverbbehav00044-0003.pdf. Acesso em 15 abr. 2021.

MILLER, Monica Campbell. et al. Effects of friendship circles on the social interactions of elementary age students with mild disabilities. Journal of Behavioral Education, 12(3), 167-184. (2003). Disponível em:

https://link.springer.com/article/10.1023/A:1025556226951. Acesso em 15 abr. 2021. Doi: 10.1023/A:1025556226951

MUELLER, Michael M.; EDWARDS, Ron P.; TRAHANT, Dana. Translating multiple assessment techniques into an intervention selection model for classrooms. Journal of Applied Behavior Analysis, 36(4), 563-573. (2003). Disponível em:

https://www.ncbi.nlm.nih.gov/pubmed/14768673. Acesso em: 15 abr. 2020. Doi: 10.1901/jaba.2003.36-563.

NEEF, Nancy A.; IWATA, Brian A.; PAGE, Terry J. The effects of interspersal training versus high-density reinforcement on spelling acquisition and retention. Journal of Applied Behavior Analysis, 13(1), 153-158. (1980). Disponível em:

https://www.ncbi.nlm.nih.gov/pmc/articles/PMC1308115/pdf/jaba00047-0153.pdf. Doi: 10.1901/jaba.1980.13-153.

NELSON, C. Michael; POLSGROVE, Lewis. Behavior Analysis in Special Education: White Rabbit or White Elephant? Remedial and Special Education, 5(4), 6-17. (1984). Disponível em: https://journals.sagepub.com/doi/10.1177/074193258400500404. Acesso em 17 abr. 2021. Doi: 10.1177/074193258400500404.

NICOLINO, Victor Faria; ZANOTTO, Maria de Lourdes Bara. Revisão histórica de pesquisas em Análise do Comportamento e educação especial/inclusão publicadas no JABA entre 2001 e 2008. Psicologia: Teoria e Prática, 12(2), 51-79. (2010). Disponível em: http://pepsic.bvsalud.org/pdf/ptp/v12n2/v12n2a05.pdf. Acesso em 17 abr. 2021.

NICOLINO, Victor Faria; ZANOTTO, Maria de Lourdes Bara. Trabalhos em análise do comportamento na área de Educação em periódicos brasileiros no período de 1961 a 2006. Acta Comportamentalia, 19(3), 343-358. (2011). Disponível em: http://pepsic.bvsalud.org/pdf/actac/v19n3/a06.pdf. Acesso em: 17 abr. 2021.

NÓBREGA, Fernando. Pereira. A análise do comportamento e educação: o estado do conhecimento de teses e dissertações produzidas de 2005 a 2015 (Dissertação de mestrado). Programa de Pós-Graduação em Educação, Universidade Federal da Bahia, Salvador, BA, Brasil. (2018).

NUNES, L. R. O. P. (Orgs.). Novas Trilhas no modo de fazer pesquisa em Educação Especial. São Carlos: Marquezine e Manzini. (2014). 
OSBORNE, J. Grayson. Free-time as a reinforcer in the management of classroom behavior. Journal of Applied Behavior Analysis, 2(2), 113-118. (1969). Disponível em: https://www.ncbi.nlm.nih.gov/pmc/articles/PMC1311048/pdf/jaba00080-0037.pdf. Acesso em 17 abr. 2021. Doi: 10.1901/jaba.1969.2-113

OSBORNE, J. Grayson; GATCH, Michael B. Stimulus equivalence and receptive reading by hearing-impaired preschool children. Language, Speech, and Hearing Services in Schools, 20(1), 63-75. (1989). Disponível em:

https://pubs.asha.org/doi/abs/10.1044/0161-1461.2001.63. Acesso em 17 abr. 2021. Doi: 10.1044/0161-1461.2001.63.

OSBORNE, J. Grayson; WAGEMAN, R. M. Some operant conditioning techniques and their use in school for the deaf. American Annals of the Deaf, 114(4), 741-53. (1969). Disponível em: https://www.ncbi.nlm.nih.gov/pubmed/4900047. Acesso em 17 abr. 2021.

PLETSCH, Márcia Denise; FONTES, Rejane de S.; GLAT, Rosana. Pesquisas com abordagem etnográfica sobre a inclusão de pessoas com necessidades educacionais especiais no ensino regular. IN: Anais IV Congresso Brasileiro Multidisciplinar de Educação Especial. Londrina: UEL. (2007).

RASING, Eef J.; DUKER, Pietter C. Effects of multifaceted training procedure on the acquisition and generalization of social behaviors in language-disable deaf children. Journal of Applied Behavior Analysis, 25(3), 723-734. (1992). Disponível em: https://www.ncbi.nlm.nih.gov/pmc/articles/PMC1279754/pdf/jaba00017-0209.pdf. Acesso em: 17 abr. 2021. Doi: 10.1901\%2Fjaba.1992.25-723.

RASING, Eef. J. Effects of a multifaceted training procedure on the social behaviors of hearing-impaired children with severe language disabilities: a replication. Journal of Applied Behavior Analysis, 26(3), 405-406. (1993). Disponível em:

https://www.ncbi.nlm.nih.gov/pmc/articles/PMC1297765/pdf/jaba00013-0129.pdf. Acesso em: 17 abr. 2021. Doi: 10.1901/jaba.1993.26-405.

SANTOS, R. E. A.; ELIAS, N. C. Contribuições da análise do comportamento para a Educação Especial em periódicos brasileiros no período de 2008 a 2018. Revista Educação Especial, 32, 1-25. (2019). Disponível em: https://periodicos.ufsm.br/educacaoespecial/article/view/38150/html. Acesso em 17 abr. 2021. Doi: $10.5902 / 1984686 \times 38150$.

SHORE, Bridget $A$. et al. Use of texture fading in the treatment of food selectivity. Journal of Applied Behavior Analysis, 31(4), 621-633. (1998) Disponível em:

https://www.ncbi.nlm.nih.gov/pmc/articles/PMC1284152/pdf/9891398.pdf. Acesso em 17 abr. 2021. Doi: 10.1901/jaba.1998.31-621.

SIDMAN, Murray. Equivalence Relations and Behavior: A Research Story. Boston: Authors Cooperative Publisher. (1994).

SIDMAN, Murray. Reading, and auditory-visual equivalences. Journal of Speech and Hearing Research, 14, 5-13. (1971). Doi: 10.1044/jshr.1401.05. 
http://dx.doi.org/10.5902/1984686X65604

SIDMAN, Murray; TAILBY, W. Conditional Discrimination vs. matching to sample: an expansion of the testing paradigm. Journal of Experimental Analysis of

Behavior, 37(1), 5-22. (1982). Doi: 10.1901/jeab.1982.37-5.

SKINNER, Burrhus Frederic. Verbal Behavior. New York: Appleton-Century-Crofts. (1957).

SMEETS, Paul M.; STRIEFEL, Sebastian. The effects of different reinforcement conditions on the test performance of multihandicapped deaf children. Journal of Applied Behavior Analysis, 8(1), 83-89. (1975). Disponível em:

https://www.ncbi.nlm.nih.gov/pmc/articles/PMC1311821/pdf/jaba00055-0085.pdf.. Acesso em 17 abr. 2021. Doi: 10.1901/jaba.1975.8-83.

STOKOE, W. C. Sign language structure: An outline of the visual communication systems of the American deaf. Journal of Deaf Studies and Deaf Education, 10 (1), 3-37. (2005). (Originalmente publicado em 1960)

SULZER-AZAROFF, Beth; GILLAT, Alex. Trends in Behavior Analysis in Education. Journal of Applied Behavior Analysis, 23 (4), 491-495. (1990). Disponível em: https://www.ncbi.nlm.nih.gov/pmc/articles/PMC1286264/pdf/jaba00090-0102.pdf. Acesso em 17 abr. 2021. Doi: 10.1901\%2Fjaba.1990.23-491.

SUNDBERG, Mark L. 301 Research topics from Skinner's Book Verbal Behavior. The Analysis of Verbal Behavior, 9, 81-96. (1991). Disponível em:

https://www.ncbi.nlm.nih.gov/pmc/articles/PMC2748536/pdf/anverbbehav00036-0083.pdf. Acesso em 17 abr. 2021.

SUNDBERG, Mark. L. Selecting a response form for nonverbal persons: Facilitated communication, pointing systems, or sign language? The Analysis of Verbal Behavior, 11, 99-116. (1993). Disponível em:

https://www.ncbi.nlm.nih.gov/pmc/articles/PMC2748559/pdf/anverbbehav00034-0100.pdf. Acesso em 17 abr. 2021.

SUTTON, Valerie. Sign writing for everyday use. Newport Beach: Sutton Movement Writing Press. (1981).

TRUMP, Cary E. et al. Applied Behavior Analysis in Special Education: Misconceptions and Guidelines for Use. Teaching Exceptional Children, 20(10), 1-13. (2018). Disponível em: https://journals.sagepub.com/doi/abs/10.1177/0040059918775020?journalCode=tcxa. Acesso em 17 abr. 2021. Doi: 10.1177/0040059918775020.

WARD, Phillip; JOHNSON, Melissa; KONUKMAN, Ferman. Direct rehearsal and preservice teachers' performance of instructional behaviors. Journal of Behavioral Education, 8(3), 369-380. (1998).

WILSON, Michele Drisko; MCREYNOLDS, Leija V. A procedure for increasing oral reading rate in hard-of-hearing children. Journal of Applied Behavior Analysis, 6(2), 231-239. (1973). Disponível em: https://onlinelibrary.wiley.com/doi/epdf/10.1901/jaba.1973.6-231. Acesso em 17 abr. 2021. Doi: 10.1901/jaba.1973.6-231. 
WOLERY, Mark. et al. Instructive Feedback: A comparison of simultaneous and alternating presentation of non-target stimuli. Journal of Behavioral Education, 3(2), 187-204. (1993). Disponível em: https://link.springer.com/article/10.1007/BF00947035. Acesso em 17 abr. 2021. Doi: 10.1007/BF00947035.

\section{Notas}

${ }^{1}$ Para mais detalhes sobre as escolas filosóficas da surdez ver Capovilla (2000).

${ }^{2} \mathrm{~A}$ comunicação facilitada envolve uma forma de resposta que consiste em palavras escritas, produzidas digitando ou apontando para letras, com a ajuda de um facilitador que guia o braço, mão ou dedo do aluno (SUNDBERG, 1993). A comunicação alternativa (MANZINI; DELIBERATO, 2004) envolveria tanto formas não apoiadas como apoiadas de comunicação. As formas apoiadas englobam os procedimentos envolvendo instrumentos "fora do corpo do usuário", como por exemplo, pranchas fotográficas ou símbolos gráficos. Na comunicação alternativa não apoiada, os recursos utilizados são comportamentos alternativos emitidos pelo próprio sujeito, por exemplo, sinais manuais, piscar para "sim" ou "não" e expressões faciais (MANZINI; DELIBERATO, 2004). 